\title{
Inflation, Oil Price Volatility and Monetary Policy*
}

\author{
Paul Castillo ${ }^{\dagger} \quad$ Carlos Montoro Vicente Tuesta $^{\ddagger}$
}

First version, October 2005

This version, January 2010

\begin{abstract}
In a fully micro-founded New Keynesian framework, we characterize analytically the relation between average inflation and oil price volatility by solving the rational expectations equilibrium of the model up to second order of accuracy. Higher oil price volatility induces higher levels of average inflation. We also show that when oil has low substitutability and the central bank responds to output fluctuations, oil price volatility matters for the level of average inflation. The model shows that when oil price volatility increases, average inflation increases whereas average output falls: this implies a trade-off also between average inflation and that of output. The analytical solution further indicates that for a given level of oil price volatility, average inflation is higher when marginal costs are convex in oil prices, the Phillips Curve is convex, and the degree of relative price dispersion is also higher. We perform a numerical exercise showing that the model with a empirically plausible Taylor rule can replicate the level of average inflation observed in the U.S. in 2000s.
\end{abstract}

JEL Classification: E52, E42, E12, C63

Keywords: Oil price volatility, monetary policy, perturbation method, second order solution.

\footnotetext{
${ }^{*}$ We would like to thank Pierpaolo Benigno, Gianluca Benigno, Juan Dolado, John Driffill, Jordi Galí, Alberto Humala, Chris Pissarides, Pau Rabanal, Hajime Tomura, Marco Vega and participants at the research workshop at the Banco Central de Reserva del Perú, the First Research Workshop on Monetary Policy Asset Prices and Oil Prices co-organized by the CCBS - Central Bank of Chile and the 12th International Conference on Computing in Economics and Finance held in Cyprus for useful suggestions and comments. The views expressed herein are those of the authors and do not necessarily reflect those of the Banco Central de Reserva del Perú.

${ }^{\dagger}$ Banco Central Reserva del Perú.

${ }^{\ddagger}$ Banco Central Reserva del Perú and CENTRUM-Católica. Corresponding author: Carlos Montoro (Email: carlos.montoro@bcrp.gob.pe), Jr. Miroquesada \#441, Lima-Perú. (511)-6132060

${ }^{\S}$ CENTRUM-Católica.
} 


\section{Introduction}

This paper offers a closed-form solution for the link between inflation and oil price volatility: higher oil price volatility induces higher levels of average inflation. This link shifts with several factors. We show that when oil has low substitutability and monetary policy reacts more aggressively towards output fluctuations, oil price volatility has a larger impact over average inflation. Thus, both monetary policy and the properties of oil have important implications in the determination of the link between oil price volatility and inflation.

Very well known empirical evidence motivates our work. The past forty years were characterized by many periods of oil price shocks with different implications on both economic activity and inflation. For instance, during the 1970s following the oil price shock (1973 and 1979), inflation peaked substantially and GDP declined as well. Nevertheless, in the most recent period (2002 onwards) the USA economy has experienced an oil price shock of similar magnitude comparable to that of the 1970s, however, in distinction with the previous episode both GDP growth and inflation have remained relatively stable. Similarly, if we further explore the link between oil price volatility (measured as the standard deviation of oil price) and both average inflation and output, we attain that larger oil price volatility was associated to high levels of inflation and low levels of output during the 1970s, whereas this link seems to be broken down in the 2000s. These different episodes pose questions regarding the link between oil price volatility and inflation: Does oil price volatility matters for the level of inflation?, why the link between oil price volatility and inflation has changed recently?, if oil price matters what would be the role of monetary policy?

Blanchard and Gali (BG, 2008) addressed some of the above questions using a log-linear New Keynesian model that includes the role of oil as both a production factor and a component of the consumer price index. BG show that a monetary policy improvement, good luck, more flexible labor markets and smaller share of oil in production have had an important role in explaining the different macroeconomic performance between the 1970s and 2000s. The loglinear approximation, however, might offer an inaccurate solution when shocks are relatively large, substantially increasing the approximation error of the model's solution. Indeed, as the empirical evidence corroborates, oil price shocks are hefty compared to other shocks usually appended in traditional new-Keynesian models (like monetary and productivity shocks). More importantly, the log-linear solution misses crucial channels through which oil price affect inflation, such as its own volatility, the precautionary behavior of price setters and the convexity of the Phillips Curve. In a nutshell, a log-linear solution is incapable to tell us something about a link between oil price volatility and average inflation.

Thus, in this paper we complement BG work and deal with the aforementioned limitations 
arising from log-linear approximations by providing a tractable and unified framework to analyze the effects of oil price volatility on inflation. Our framework allows us to shed additional light beyond those offered by log-linear solutions on the nature of the apparent changes in the macroeconomic effects of oil prices. In essence, we establish the link between oil price volatility and average inflation. In doing so, we use a standard New Keynesian micro-founded model with staggered Calvo pricing where the central bank implements its policy following a Taylor rule. We modify this simple framework considering oil as a production input for intermediate good that is difficult to substitute in production. Then, we solve up to second order of accuracy the rational expectations equilibrium of this model using the perturbation method developed by Schmitt-Grohé and Uribe (2004).

The second order solution has the advantage of incorporating the effects of shocks volatility in the equilibrium, which are absent in the linear solution. We implement this method both analytically and numerically. As part of our contribution, we use an original strategy to obtain an analytical solution. Thus, different from other papers in the literature such as Aruoba et. al. (2006) and Schmitt-Grohé and Uribe (2005), in which the perturbation method is applied directly to the non-linear system of equations, we first approximate the model up to second order and then apply the perturbation method to the approximated model. This strategy permits us to disentangle the key determinants of the relationship between oil price volatility and inflation and to quantify the importance of each determinant in general equilibrium.

Our basic finding indicates that the second order analytical solution - by relaxing certainty equivalence- permits us establishing a link between oil price volatility and average inflation. Just to highlight some parallelism, this level of inflation generated by oil price volatility is similar to the effect of consumption volatility on the level of average savings studied in the literature of precautionary savings. Indeed, the solution up to second order shows that oil price volatility produces an extra level of inflation by altering the way in which forward-looking firms set their prices. This mechanism is absent in log-linear solutions and the link arises from the forward-looking behavior of the optimizing agents.

On the sources of the link between oil price volatility and inflation, the analytical solution shows the following: first, when oil has low substitutability, marginal costs are convex in oil price, hence, its price volatility raises the expected value of marginal costs. Second, oil price volatility in itself generates inflation volatility, thus inducing price setters to be more cautious to future expected marginal costs. In particular, producer relative prices become more sensitive to marginal costs, amplifying the previous channel. Third, relative price dispersion, by increasing the amount of labor required to produce a given level of output, increases average wages, thus amplifying the effect of expected marginal costs over average inflation. Fourth, in general equilibrium, the weights that the central bank assigns on inflation and output 
are key determinants for the level of inflation induced by oil price volatility. As a result, our model predicts that the smaller (larger) the endogenous responses of a central bank to inflation (output) fluctuations, the greater the average inflation (smaller average output). Thus, changes in the way monetary policy was conducted may explain different responses of the economy to oil price volatility and oil shocks. This finding is consistent with the fact that, in the model, oil price generates a monetary policy trade-off between stabilizing inflation and output, which traduces to a policy trade-off in means as well.

We also evaluate the implications of analytical results of the model by performing a first pass numerical exercise calibrated for the U.S. economy. Overall, our results are broadly consistent with predictions of the analytical solution. In addition, we are able to generate a level of average inflation similar to the one observed during the 2000s. We show that the commitment of U.S. central bank to maintain low and stable levels of inflation, helped to improve the trade-off between inflation and output in 2000s, despite oil price volatility was of similar magnitude to that observed in the 1970s. We further find others factors important in explaining the link between inflation and oil price volatility in the 2000s. For example, the convexities of the Phillips curve and price dispersion explain 44 and 38 percent, respectively, of the level of average inflation in the 2000s. Last but not least, we devote a section to analyze the accuracy of the second order approximation showing the gains of it, relative to the linear solution, in terms of errors of the inflation's equation.

Other authors introduced the second order approach in closed and open economies; however, most of the studies have mainly focused on welfare evaluations across different environments. For example Benigno and Woodford (2003) implemented the second order solution to evaluate optimal monetary and fiscal policy in a closed economy. Benigno and Benigno (2005) used the second order approach to evaluate the optimal policy in a two-country model with complete markets. Two studies could be seen, methodologically, closer to our work. Evans and Hnatkovska (2005) evaluated the role of uncertainty in explaining differences in the holding of assets in two-country models and Obstfeld and Rogoff (1998) developed an explicit stochastic NOEM model relaxing the assumption of certainty equivalence. The latter authors, based on simplified assumptions, obtained an analytical solution for the level exchange rate premium. Different from the aforementioned two studies, in this paper we obtain an analytical solution for the extra level of inflation arising from the second order approximation using a fully micro-founded New Keynesian model with oil prices.

The rest of the paper is organized as follows. Section 2 presents some basic facts for the US economy to motivate on the link between oil price volatility and inflation. In also provides a simple model that supports the link. Section 3 presents the model. Section 4 explains the mechanism at work in generating the link between oil prices and inflation. Section 5 uses the 
model to analyze the role of oil price volatility and monetary policy for the level of average inflation and perform some numerical exercises. Section 6, for robustness, analyzes the degree of accuracy of the second order solution. Finally section 7 concludes.

\section{Motivation}

\subsection{Average inflation and oil price volatility}

Inspection of US inflation and oil price data seems to suggest that both inflation rate and oil prices have moved together from 1970 until 1999. However, from 2000 onwards this positive comovement has broken down. Figure 1 displays the evolution of the real price of oil and inflation both in logs since 1970. We measure oil price as the log spot price West Texas Intermediate minus log SA non-farm business sector deflator and our measure of inflation is the variation of the consumer price index. The figure shows that, from 1970 until the beginning of 2000s, the dynamics of inflation evolves closely to that of oil price. Thus, for the period 1970-1980 we observe a persistent initial increase in inflation vis-à-vis a jump in oil price following the oil price shock in 1974. From 1980 to 1999 we observe a steady decline in inflation accompanied by a persistent drop in oil price. Unlike the first two sub-samples, from 2002 onwards the Figure shows a markedly upward trend in oil price and a moderate increase in inflation. It seems that the positive relationship between inflation and oil price became weaker during the more recent period.

This different dynamics witnessed during the 2002s is also evident when comparing the standard deviation of oil price with average inflation across the same sub-samples ${ }^{1}$. Table 1 reports the standard deviations and averages levels of both oil price and inflation for the three sub-samples, 1970-1983, 1984-2002 and 2002-2008. Again, by comparing the first and second sub-samples, note that a high level of average inflation and high volatility of oil price characterizes the first one, whereas a lower level of both average inflation and volatility of oil price typifies the second one. This very simple evidence indicates a positive relationship between oil price volatility and average inflation during the two first sub-samples. Nevertheless, in the 2000s this relation has changed dramatically. From 2002-2008, oil price volatility is as large as the one reported in the first sub-sample (1.49 in 2000s versus 1.55 in 1970s), however, the average level of inflation is three times smaller. The description of these stylized facts is not altered if we use other measures of inflation and oil price.

\footnotetext{
${ }^{1}$ BG identify four shocks using as a definition of oil shock as an episode involving a cumulative change in the (log) price of oil above 50 percent, sustained for more than four quarters. Our two first sub-samples contain the three first identified shocks and the last sub-sample contains the fourth shock reported in BG.
} 


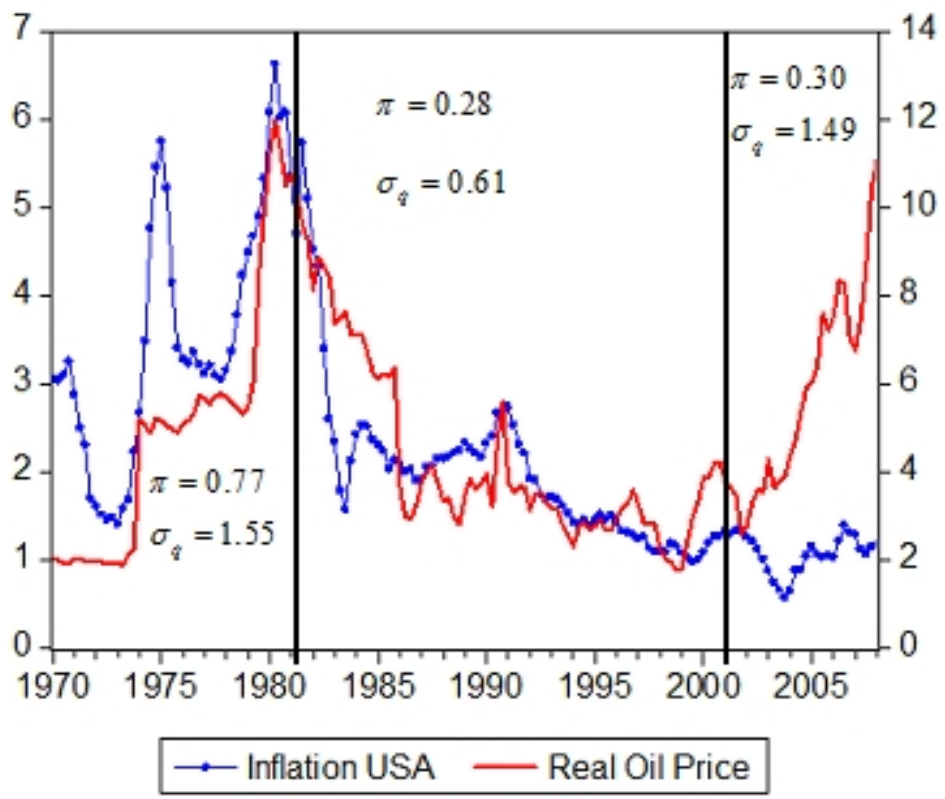

Figure 2.1: U.S. Inflation and Real Oil Price

Table 1: Inflation and Real Oil Price

\begin{tabular}{lccc}
\hline \hline & (I) $1970-1983$ & (II) $1984-2002$ & (III) 2002-2008 \\
\hline S.D. Inflation & 0.77 & 0.28 & 0.30 \\
S.D. Real Oil Price & 1.55 & 0.61 & 1.49 \\
Mean Inflation & 1.57 & 0.53 & 0.57 \\
Mean Real Oil Price $(1970=1)$ & 2.87 & 2.17 & 4.30 \\
\hline \hline
\end{tabular}

We summarize the evidence reported above as follows: First, there is a positive link between oil price volatility and average inflation rate during the first two sub-samples. Second, this positive link has broken down from 2002 onwards. The above two pieces of evidence are the main motivation of our paper. In the next sections, first we develop a new Keynesian model that permits us to obtain, analytically, a positive link between oil price volatility and average inflation. Second, with the model and the link at hand, we explore the reasons why this link might have been broken down or has been less important during the 2000s.

\subsection{The link in a simple model}

Before moving to a general equilibrium analysis, in this section we use a simple model to establish a link between average inflation and oil price volatility. Suppose that firms producing differentiated goods set prices one period in advance. They also face a downward sloping 
demand function of the type, $Y_{t}(z)=\left(\frac{P_{t}^{*}(z)}{P_{t}}\right)^{-\varepsilon} Y$, where $\varepsilon$ represents the elasticity of substitution across goods and $Y$ aggregate output, which is fixed. Under these assumptions, the optimal pricing decision of a particular firm $z$ for time $t$ is given by a mark-up over the expected next period marginal cost,

$$
\frac{P_{t}^{*}(z)}{P_{t-1}}=\mu E_{t-1}\left[\Psi_{t} M C_{t}\right]
$$

where $\mu, M C_{t}$ and $\Psi_{t}=\frac{\Pi_{t}^{\varepsilon+1}}{E_{t-1} \Pi_{t}^{\varepsilon}}$ denote the mark-up, firm's marginal costs and a measure of the responsiveness of the optimal price to future marginal costs, respectively. The previous arguments are standard in new Keynesian frameworks. A second order Taylor expansion of the expected responsiveness to marginal cost, $\Psi_{t}$, is given by:

$$
E_{t-1}\left[\Psi_{t}\right]=E_{t-1}\left[\pi_{t}+\frac{1}{2}(2 \varepsilon+1) \pi_{t}^{2}\right]
$$

From the above expression it is clear that $E_{t-1} \Psi_{t}$ is a convex function of expected inflation. This convexity implies that inflation volatility increases the weight that a firm assigns on expected marginal costs. Thus, for the same level of marginal costs, an increase in inflation volatility generates a rise in inflation.

To gain further insights, let us assume the following quadratic marginal cost function in terms of oil prices (the only input for production is oil)

$$
M C_{t}=\phi_{1} q_{t}+\frac{\phi_{2}}{2} q_{t}^{2}
$$

where $q_{t}$ denotes the real price of oil, $\phi_{1}>0$ measures the linear effect of oil over the marginal cost and $\phi_{2}$ accounts for the impact of oil price volatility on marginal costs. When $\phi_{2}>0$, marginal costs are convex in oil prices, hence expected marginal costs become an increasing function of oil price volatility. ${ }^{2}$

Different forms of aggregation of sticky prices in the literature show that the inflation rate is proportional to the optimal relative price of firms (equation (2.1)). Thus, when marginal costs are convex, both the optimal relative price and inflation are increasing in oil price volatility.

More importantly, other channels amplify the previous effect. To the extent that oil price volatility induces an increase in inflation volatility, price setters react by augmenting the weight on marginal costs, $\Psi_{t}$, when setting their prices. As equation (2.2) indicates, up to second order, the weight, $\Psi_{t}$, depends not only on the level of expected inflation but also on its volatility. Nevertheless, it is fair to raise the question whether or not those second order effects are

\footnotetext{
${ }^{2}$ In section 4 we show that when the production function is a CES with an elasticity of substitution between labor and oil lower than one, marginal costs are convex in oil prices, that is $\phi_{2}>0$.
} 
important. As it will become clearer later in the paper, two special features of oil prices are crucial to make those second order effects quantitative sizable: a) its high volatility and b) its low substitutability with other production factors.

A linear approximation that omits the role of both oil price and inflation volatilities would not capture the effects of oil price volatility over average inflation. In contrast, the second order solution of the rational expectations equilibrium of the model allows us to include volatility terms as determinants of the level of average inflation.

So far we showed that a second order solution allows us to establish a positive link between the volatility of oil prices and the average level of inflation. Indeed, this positive relationship can potentially explain the empirical evidence during the 1970s, that is, the higher the volatility of oil price the higher the average level of inflation.

Note also that in a micro-founded new Keynesian framework, $\phi_{1}$ and $\phi_{2}$ represent reduced form parameters. For example, in such an environment, $\phi_{2}$ measures the sensitivity of the average level of inflation to oil price volatility, and it will depend on deep parameters, among them, those associated with the conduct of monetary policy (reaction function). Thus as an example, if $\phi_{2}$ falls due to a change in the central bank reaction function (i.e. more aggressive towards inflation), the effect of oil price volatility, $q_{t}^{2}$, can be dampened and even completely offset. This is consistent with the hypothesis that monetary policy has been more aggressive in the late 1990s than in the 1970s. In the next section we formalize this link by deriving a second order rational expectations solution of a New Keynesian general equilibrium model with oil prices.

\section{A new Keynesian model with oil prices}

The model economy corresponds to the standard New Keynesian model. We follow Blanchard and Gali (2008) in introducing a non-produced input $M$, represented in this case by oil. $Q$ denotes the real price of oil which is exogenous.

\subsection{Households}

We assume the following utility function on consumption and labour of the representative consumer

$$
U_{t_{o}}=E_{t_{o}} \sum_{t=t_{o}}^{\infty} \beta^{t-t_{o}}\left[\frac{C_{t}^{1-\sigma}}{1-\sigma}-\frac{L_{t}^{1+v}}{1+v}\right],
$$

where $\sigma$ and $\nu$ represent the coefficient of risk aversion and the inverse of the elasticity of labor supply, respectively. The optimizer consumer takes decisions subject to a standard budget 
constraint which is given by

$$
C_{t}=\frac{W_{t} L_{t}}{P_{t}}+\frac{B_{t-1}}{P_{t}}-\frac{1}{R_{t}} \frac{B_{t}}{P_{t}}+\frac{\Gamma_{t}}{P_{t}}+\frac{T_{t}}{P_{t}}
$$

where $W_{t}$ is the nominal wage, $P_{t}$ is the price of the consumption good, $B_{t}$ is the end of period nominal bond holdings, $R_{t}$ is the nominal gross interest rate, $\Gamma_{t}$ is the share of the representative household on total nominal profits, and $T_{t}$ are transfers from the government. ${ }^{3}$ The first order conditions for the optimizing consumer's problem are:

$$
\begin{gathered}
1=\beta E_{t}\left[R_{t}\left(\frac{P_{t}}{P_{t+1}}\right)\left(\frac{C_{t+1}}{C_{t}}\right)^{-\sigma}\right], \\
\frac{W_{t}}{P_{t}}=C_{t}^{\sigma} L_{t}^{\nu}=M R S_{t} .
\end{gathered}
$$

Equation (3.3) is the standard Euler equation that determines the optimal path of consumption. At the optimum the representative consumer is indifferent between consuming today or tomorrow, whereas equation (3.4) describes the optimal labor supply decision. $M R S_{t}$ denotes the marginal rate of substitution between labor and consumption. We assume that labor markets are competitive and also that individuals work in each sector $z \in[0,1]$. Therefore, $L$ corresponds to the aggregate labor supply:

$$
L=\int_{0}^{1} L_{t}(z) d z
$$

\section{$3.2 \quad$ Firms}

\subsubsection{Final goods producers}

There is a continuum of final goods producers of mass one, indexed by $f \in[0,1]$ that operate in an environment of perfect competition. They use intermediate goods as inputs, indexed by $z \in[0,1]$ to produce final consumption goods using the following technology:

$$
Y_{t}^{f}=\left[\int_{0}^{1} Y_{t}(z)^{\frac{\varepsilon-1}{\varepsilon}} d z\right]^{\frac{\varepsilon}{\varepsilon-1}}
$$

where $\varepsilon$ is the elasticity of substitution between intermediate goods. Then the demand function of each type of differentiated good, is obtained by aggregating the input demand of final good

\footnotetext{
${ }^{3}$ The government owns the oil's endowment which is produced in the economy at zero cost and sold to the firms at an exogenous price. The government transfers all the revenues generated by oil to consumers, that is: $\frac{T_{t}}{P_{t}}=Q_{t} M_{t}$.
} 
producers

$$
Y_{t}(z)=\left(\frac{P_{t}(z)}{P_{t}}\right)^{-\varepsilon} Y_{t},
$$

where the price level is equal to the marginal cost of the final good producers and is given by:

$$
P_{t}=\left[\int_{0}^{1} P_{t}(z)^{1-\varepsilon} d z\right]^{\frac{1}{1-\varepsilon}}
$$

and $Y_{t}$ represents the aggregate level of output.

$$
Y_{t}=\int_{0}^{1} Y_{t}^{f} d f
$$

\subsubsection{Intermediate goods producers}

There is a continuum of intermediate good producers indexed by $z \in[0,1]$. All of them have the following CES production function

$$
Y_{t}(z)=\left[(1-\alpha)\left(L_{t}(z)\right)^{\frac{\psi-1}{\psi}}+\alpha\left(M_{t}(z)\right)^{\frac{\psi-1}{\psi}}\right]^{\frac{\psi}{\psi-1}},
$$

where $M$ is oil which enters as a non-produced input, $\psi$ represents the intratemporal elasticity of substitution between labor-input and oil and $\alpha$ denotes the share of oil in the production function. We use this generic production function to account for the fact that oil has few substitutes $(\psi<1)$. Since oil has few substitutes an appealing functional form to capture this feature is the CES production function. This function offers flexibility in the calibration of the degree of substitution between oil and labor. ${ }^{4}$ The oil price shock, $Q_{t}$, follows an $A R(1)$ process in logs,

$$
\log Q_{t}=(1-\rho) \log \bar{Q}+\rho \log Q_{t-1}+\varepsilon_{t},
$$

where $\bar{Q}$ is the steady state level of oil price. From the cost minimization problem of the firm we obtain an expression for the real marginal cost given by:

$$
M C_{t}(z)=\left[(1-\alpha)^{\psi}\left(\frac{W_{t}}{P_{t}}\right)^{1-\psi}+\alpha^{\psi}\left(Q_{t}\right)^{1-\psi}\right]^{\frac{1}{1-\psi}}
$$

\footnotetext{
${ }^{4}$ Some authors that have included oil in the analysis of RBC models and monetary policy, have omitted this feature. For example, Kim and Loungani (1992) assume for the U.S. a Cobb-Douglas production function between labor and a composite of capital and energy. Given that they calibrate their model considering that oil has a small share on output, they found that the impact of oil in the U.S. business cycle is small. Notice that when $\psi=1$, the production function collapses to the standard Cobb-Douglas function as the one used by Blanchard and Gali (2006): $Y_{t}(z)=\left(L_{t}(z)\right)^{1-\alpha}\left(M_{t}(z)\right)^{\alpha}$.
} 
where $M C_{t}(z), W_{t}$ and $P_{t}$ represents the real marginal cost, nominal wages and the consumer price index, respectively. Note that since technology has constant returns to scale and factor markets are competitive, marginal costs are the same for all intermediate firms, i.e. $M C_{t}(z)=$ $M C_{t}$. The individual firm's labor demand is given by:

$$
L_{t}^{d}(z)=\left(\frac{1}{1-\alpha} \frac{W_{t} / P_{t}}{M C_{t}}\right)^{-\psi} Y_{t}(z)
$$

Intermediate producers set prices following a staggered pricing mechanism a la Calvo. Each firm faces an exogenous probability of changing prices given by $(1-\theta)$. The optimal price that solves the firm's problem is given by

$$
\left(\frac{P_{t}^{*}(z)}{P_{t}}\right)=\frac{\mu E_{t}\left[\sum_{k=0}^{\infty} \theta^{k} \zeta_{t, t+k} M C_{t+k} F_{t, t+k}^{\varepsilon+1} Y_{t+k}\right]}{E_{t}\left[\sum_{k=0}^{\infty} \theta^{k} \zeta_{t, t+k} F_{t, t+k}^{\varepsilon} Y_{t+k}\right]},
$$

where $\mu \equiv \frac{\varepsilon}{\varepsilon-1}$ is the price markup, $\zeta_{t, t+k}=\beta^{k}\left(\frac{C_{t+k}}{C_{t}}\right)^{-\sigma} \frac{P_{t}}{P_{t+k}}$ is the stochastic discount factor, $P_{t}^{*}(z)$ is the optimal price level chosen by the firm, $F_{t, t+k}=\frac{P_{t+k}}{P_{t}}$ denotes the cumulative level of inflation and $Y_{t+k}$ is the aggregate level of output. Since only a fraction $(1-\theta)$ of firms changes prices every period and the remaining share keeps its price fixed, thus the aggregate price level -the price of the final good that minimize the cost of the final goods producers- is given by the following equation:

$$
P_{t}^{1-\varepsilon}=\theta P_{t-1}^{1-\varepsilon}+(1-\theta)\left(P_{t}^{*}(z)\right)^{1-\varepsilon}
$$

Following Benigno and Woodford (2005), equations (3.14) and (3.15) can be written recursively introducing the auxiliary variables $N_{t}$ and $D_{t}$ (see appendix $B .1$ for details):

$$
\begin{gathered}
\theta\left(\Pi_{t}\right)^{\varepsilon-1}=1-(1-\theta)\left(\frac{N_{t}}{D_{t}}\right)^{1-\varepsilon}, \\
D_{t}=Y_{t}\left(C_{t}\right)^{-\sigma}+\theta \beta E_{t}\left[\left(\Pi_{t+1}\right)^{\varepsilon-1} D_{t+1}\right], \\
N_{t}=\mu Y_{t}\left(C_{t}\right)^{-\sigma} M C_{t}+\theta \beta E_{t}\left[\left(\Pi_{t+1}\right)^{\varepsilon} N_{t+1}\right] .
\end{gathered}
$$

Equation (3.16) comes from the aggregation of individual firms prices. The ratio $N_{t} / D_{t}$ represents the optimal relative price $P_{t}^{*}(z) / P_{t}$. Equations (3.16), (3.17) and (3.18) summarize the recursive representation of the non- linear Phillips curve. Writing the optimal price setting 
in a recursive way is necessary in order to implement both numerically and algebraically the perturbation method.

\subsection{Monetary policy}

The central bank conducts monetary policy by targeting the nominal interest rate according to the following Taylor-type rule

$$
R_{t}=R_{t-1}^{\phi_{r}}\left[\bar{R}\left(\frac{E_{t} \Pi_{t+1}}{\bar{\Pi}}\right)^{\phi_{\pi}}\left(\frac{Y_{t}}{\bar{Y}}\right)^{\phi_{y}}\right]^{1-\phi_{r}},
$$

where, $\phi_{\pi}>1$ and $\phi_{y}>0$ measure the response of the nominal interest rate to expected future inflation and current output, respectively. The degree of interest rate smoothing is measured by $0 \leq \phi_{r} \leq 1$. The steady state values are expressed without time subscript and with and upper bar.

\subsection{Market clearing}

Labor, intermediate and final goods markets clear. Since there is neither capital accumulation nor government sector, the economy-wide resource constraint is given by

$$
Y_{t}=C_{t}
$$

The labor market clearing condition is given by:

$$
L_{t}=L_{t}^{d}
$$

Where the demand for labor comes from the aggregation of individual intermediate producers in the same way as the labor supply:

$$
\begin{aligned}
L^{d} & =\int_{0}^{1} L_{t}^{d}(z) d z=\left(\frac{1}{1-\alpha} \frac{W_{t} / P_{t}}{M C_{t}}\right)^{-\psi} \int_{0}^{1} Y_{t}(z) d z, \\
L^{d} & =\left(\frac{1}{1-\alpha} \frac{W_{t} / P_{t}}{M C_{t}}\right)^{-\psi} Y_{t} \Delta_{t},
\end{aligned}
$$

where $\Delta_{t}=\int_{0}^{1}\left(\frac{P_{t}(z)}{P_{t}}\right)^{-\varepsilon} d z$ is a measure of price dispersion. Since relative prices differ across firms due to staggered price setting, input usage will differ as well. Thus, it is not possible to use the usual representative firm assumption. Therefore, the price dispersion factor, $\Delta_{t}$, appears in the aggregate labor demand equation. From (3.22) note that higher the price dispersion the 
larger the labor amount necessary to produce a given level of output.

\section{The second order representation}

\subsection{The second-order Taylor expansion}

As previously mentioned, the special features of oil, such as its high price volatility and its low substitutability in production, imply that oil prices can have meaningful second-order effects on inflation in addition to those usually shown to be important in log-linear models. In log-linear representations certainty equivalence holds, thus uncertainty does not play any role. Thus, to gauge the link between oil prices and inflation, a second-order solution is required. To characterize this solution, we present a log-quadratic Taylor approximation of equations (3.3), (3.4),(3.12), (3.16), (3.17), (3.18), (3.19) and (3.22) around the deterministic steady-state. ${ }^{5}$ The second-order Taylor-series expansion serves to compute the equilibrium fluctuations of the endogenous variables of the model up to a residual of order $O\left(\left\|q_{t}, \sigma_{q}\right\|^{2}\right)$ where $\sigma_{q}$ is the standard deviation of the real oil price and $\left\|q_{t}, \sigma_{q}\right\|$ denotes a bound on both the deviation of oil price from its steady state and its volatility. ${ }^{6}$ We denote variables in steady state with upper bar (i.e. $\bar{X}$ ) and their log deviations around the steady state with lower case letters (i.e. $x=\log \left(\frac{X_{t}}{X}\right)$ ). After imposing the goods and labor market clearing conditions to eliminate real wages and labor from the system, the dynamics of the economy is given by the following equations:

\footnotetext{
${ }^{5}$ Appendix B.2 provides a detailed derivation of the log-quadratic Taylor approximations. See appendix A for the derivation of the steady-state of the economy.

${ }^{6}$ Since we want to make explicit the effects of changes in oil price volatility over the equilibrium of the endogenous variables, we solve the policy functions as in Schmitt-Grohe and Uribe (2004) in terms of the shocks $\left(q_{t}\right)$ and its volatility, $\left(\sigma_{q}\right)$. This approach is different to the one undertook by Benigno and Woodford (2003), for example, who considers a policy function in terms of the shocks only $\left(e_{t}\right)$.
} 
Table 2: Second order Taylor expansion of the equations of the model

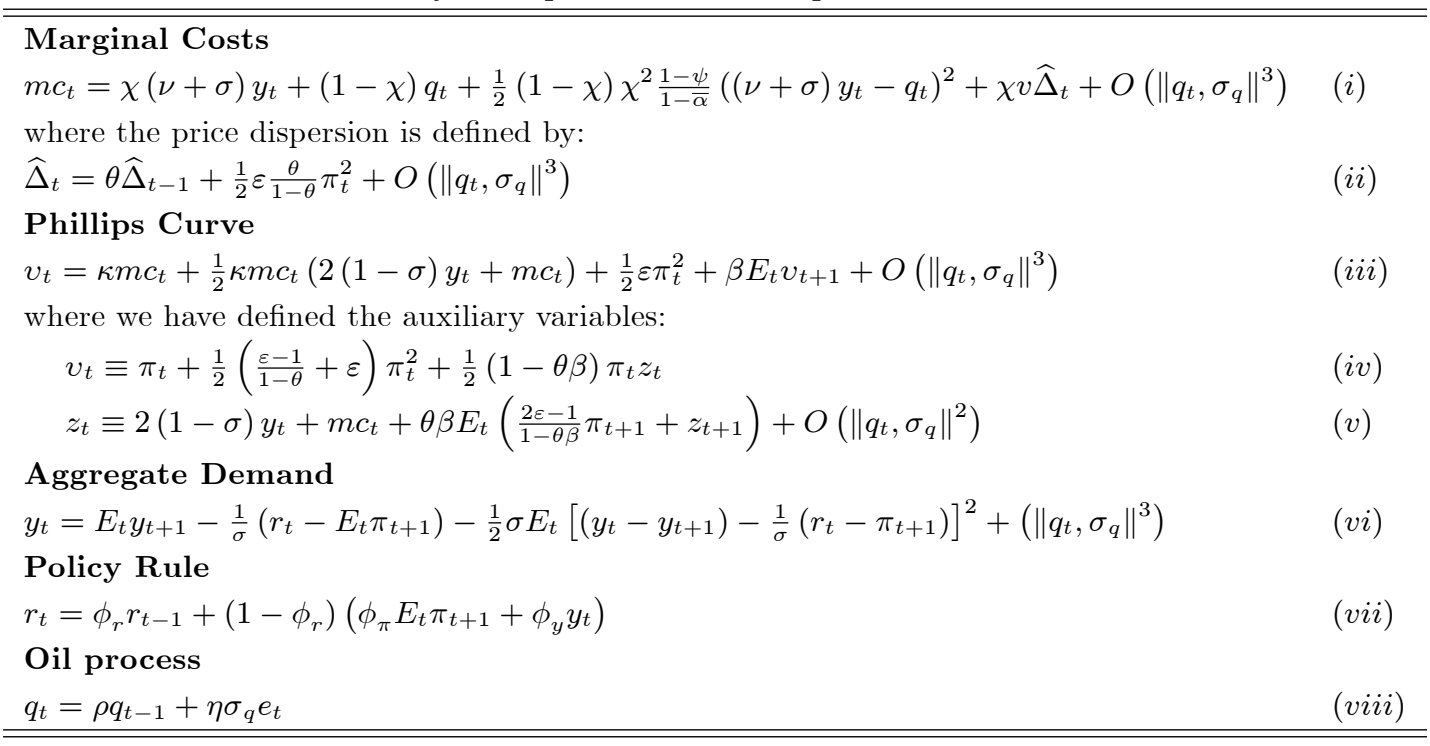

where $\chi \equiv \frac{1-\bar{\alpha}}{1+v \psi \bar{\alpha}}, \bar{\alpha} \equiv \alpha^{\psi}\left(\frac{\bar{Q}}{\overline{M C}}\right)^{1-\psi}, \kappa \equiv \frac{1-\theta}{\theta}(1-\theta \beta)$, and $\bar{Q}$, and $\overline{M C}$ denote the steady-state value of oil price and marginal costs, respectively. The first five equations of table 2 summarize the second-order expansion of the aggregate supply curve, whereas the sixth equation is the second-order expansion of the aggregate demand. We obtained equation (i) by taking a second-order Taylor-series expansion to the real marginal cost equation after replacing real wages with its equilibrium determinants. The term $\widehat{\Delta}_{t}$, equation (ii), is the log-deviation of the measure of price dispersion $\Delta_{t}$, which is a second order function of inflation. Overall, these equations indicate that in an economy with volatile oil prices, not only expected marginal costs, expected oil price, and expected future inflation matter for inflation dynamics but also their second moments. For instance, the second order approximation adds two new ingredients to the determination of the marginal cost. The first one is related to the convexity of marginal costs with respect to oil price. From equation (i) note that, when oil is difficult to substitute, $\psi<1$, the marginal cost becomes a convex function of oil price, hence, oil price volatility induces an increase in the expected marginal cost. This is an important channel through which oil price generates higher inflation rates absent when using Cobb-Douglas production function. When $\psi=1$, the marginal cost equation boils down to

$$
m c_{t}=\chi(\nu+\sigma) y_{t}+(1-\chi) q_{t}+\chi v \widehat{\Delta}_{t}
$$

Note that, in the above equation, the marginal cost does not depend directly on the volatility of oil prices $\left(q_{t}^{2}\right)$, but only indirectly through its effects on relative price dispersion term, $\widehat{\Delta}_{t}$. 
The second new ingredient in equation $(i)$ is the price dispersion term $\widehat{\Delta}_{t}$. It is clear that as price dispersion increases, the required number of hours to produce a given level of output also increases. The higher labor demand further increases real wages and therefore marginal cost also increase. This effect is higher the lower the elasticity of labor supply, $\frac{1}{v}$, and the higher the share of oil in production.

The second order representation of the aggregate demand considers also the effect of growth rate of consumption volatility on savings. Thus, when the volatility of consumption increases, consumption falls, since households increase their savings for precautionary reasons.

\subsection{The canonical representation}

Next we further simplify the model by plugging equations (i),(ii),(iv) and (v) in equation (iii), and the policy rule of the central bank (vii) in equation (vi). To make the analysis analytically tractable, we set the smoothing parameter in the Taylor rule equal to zero. Similarly, we assume an small initial price dispersion such that $\widehat{\Delta}_{t_{o}-1} \approx 0$ up to second order. ${ }^{7}$ Thus, the model collapses to a second- order system of two-equations as a function of inflation and output: an aggregate supply equation (4.1) and an aggregate demand equation (4.2) )

$$
\begin{gathered}
\pi_{t}=\kappa_{y} y_{t}+\kappa_{q} q_{t}+\beta E_{t} \pi_{t+1}+\frac{1}{2} \omega_{v} \sigma_{q}^{2}+\frac{1}{2}\left(\Omega_{m c}+\Omega_{\pi}+\Omega_{v}\right) q_{t}^{2}+O\left(\left\|q_{t}, \sigma_{q}\right\|^{3}\right) \\
y_{t}=E_{t}\left(y_{t+1}\right)-\frac{1}{\sigma}\left(\left(\phi_{\pi}-1\right) E_{t} \pi_{t+1}+\phi_{y} y_{t}\right)+\frac{1}{2} \omega_{y} \sigma_{q}^{2}+O\left(\left\|q_{t}, \sigma_{q}\right\|^{3}\right)
\end{gathered}
$$

where $\kappa_{y} \equiv \chi(\nu+\sigma) \kappa$, and $\kappa_{q} \equiv(1-\chi) \kappa$. To get the above two equations, we write the second-order terms of the endogenous variables as functions of $\sigma_{q}^{2}$ and $q_{t}^{2}$, using the first-order solution of the model as in Sutherland (2002). As equation (4.1) shows, both the conditional and unconditional variances of oil price are relevant for the determination of average inflation. The magnitude of the impact of these second moments on average inflation depends on the following "omegas" coefficients: $\Omega_{m c}$ measures the impact of $q_{t}^{2}$ on marginal costs, $\Omega_{\pi}$, on $\pi_{t}^{2}$, $\Omega_{v}$ on $v_{t}$, similarly, $\omega_{v}$ and $\omega_{y}$ measure the impact of $\sigma_{q}^{2}$ on inflation and output, respectively. Those coefficients are derived in appendix B. Note that if the aforementioned coefficients were equal to zero the model would collapse to a standard version of a New Keynesian model in log linear form. In the next section, we obtain the link between inflation and oil price volatility by solving the rational expectations equilibrium for $\left\{\pi_{t}\right\}$ and $\left\{y_{t}\right\}$ using (4.1) and (4.2). Yet, before moving to the analytical solution we perform some simulations showing how

\footnotetext{
${ }^{7}$ This notwithstanding, the numerical exercises consider the more general specification of the model and qualitatively results are broadly the same.
} 
the "omegas" coefficients depend upon deep parameters. To perform the simulation we use the benchmark parameterization of section 5.3.

$\Omega_{m c}$ coefficient measures both the direct effect of oil price volatility on marginal costs and its indirect effect through the labor market. Let's first consider the direct effect. When oil has few substitutes, $\psi<1$, the firm's marginal cost is convex in oil prices, hence, the expected marginal cost becomes an increasing function of oil price volatility. To compensate any increase in expected marginal costs triggered by oil price volatility, a forward looking firm reacts by optimally charging a higher price. In turn, this firm's response leads to higher aggregate inflation when prices are sticky. ${ }^{8}$ Interestingly, the smaller the elasticity of substitution between oil and labor inputs, the larger the increase in both marginal costs and inflation in response to oil price volatility. Oil price volatility further affects the marginal cost indirectly, through its effects on the labor market. Since oil price volatility generates inflation volatility, which is costly because it increases relative price distortions, efficiency in production falls as the volatility of oil prices rises. In particular, firms require, at the aggregate level, more hours of work to produce the same amount of output. Hence, the demand for labor rises, making labor more expensive and consequently the marginal cost and inflation augment even further.

Panels (a) and (b) in figure 4.1 depict the relation between $\Omega_{m c}$ and the elasticity of substitution between oil and labor inputs, $\psi$, and the steady state level of oil prices, $Q$, respectively. As shown in panel (a), the lower the elasticity of substitution, $\psi$, the higher the direct effect of oil price volatility over marginal costs. Moreover, the higher the steady state level of oil price, ceteris paribus, the higher the effect of oil price volatility on marginal costs. Overall these simulations suggest that economies where oil has less substitutes or oil price is large, oil price volatility in itself would have a larger impact on average inflation.

Coefficient $\Omega_{\pi}$ accounts for the effects of oil price volatility on the weight firms assign to movements in future marginal costs. When prices are sticky and firms face a positive probability of not being able to change prices, as in the Calvo price-setting model, the weight that firms assign to future marginal cost depends on both expected inflation and inflation's volatility. Thus, oil price volatility by raising inflation volatility induces price-setters to put a higher weight on future marginal costs. In a nutshell, oil price volatility not only increases expected marginal costs but also it makes the firms' relative prices to be more sensitive to future marginal costs. In fact, panel (c) in figure 2 shows that the lower the degree of price stickiness, $\theta$, the larger the effect of oil price volatility over inflation volatility, $\Omega_{\pi}$. The previous

\footnotetext{
${ }^{8}$ This mechanism can be understood by observing equation (i), where $\frac{\partial^{2} m c_{t}}{\partial q_{t}^{2}}=(1-\chi) \chi^{2} \frac{1-\psi}{1-\bar{\alpha}}$. When $\psi<$ $1(\psi>1), \frac{\partial^{2} m c_{t}}{\partial q_{t}^{2}}>0(<0)$
} 

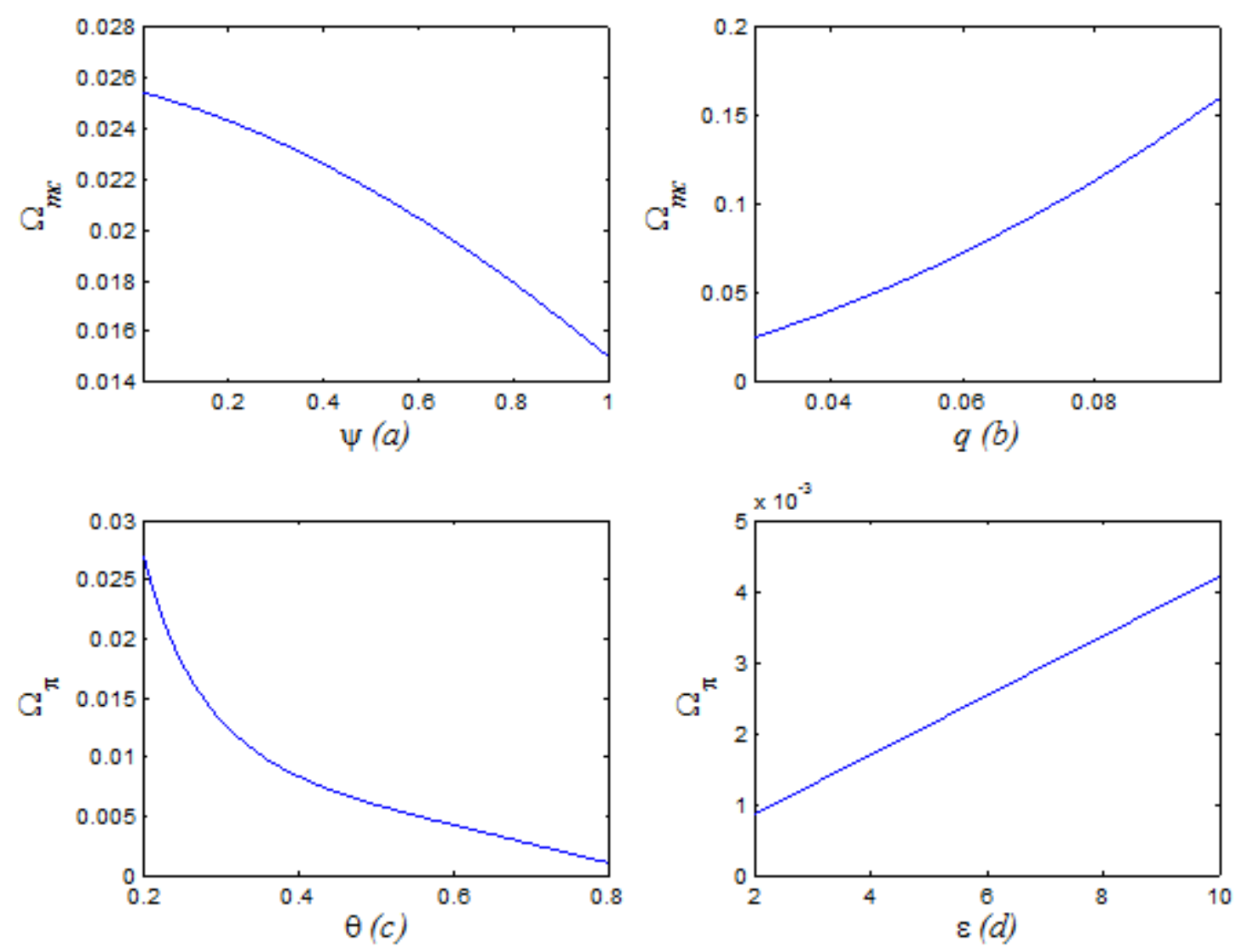

Figure 4.1: Average inflation components. 
relation comes from the fact that lower price rigidity makes the Phillips curve steeper and more convex, making the effect of inflation volatility larger. Panel (d) shows that when the elasticity of substitution of goods, $\varepsilon$, increases, the effect of inflation volatility on the individual price of firms, $\Omega_{\pi}$, increases.

Coefficients $\Omega_{v}$ and $\omega_{v}$ account for the time variant and constant effects of inflation volatility on the composite of inflation $v_{t}$, respectively. Both mechanisms are similar to the ones associated to $\Omega_{\pi}$, however, both coefficients are quantitatively small. Finally, the coefficient $\omega_{y}$ is negative and accounts for the standard precautionary savings effect, by which oil price volatility induces households to increase their savings to buffer future states of the nature when income is low.

\section{Oil price volatility and inflation in general equilibrium}

\subsection{The equilibrium level of average inflation}

We use the perturbation method to obtain the second order rational expectations solution of the model. ${ }^{9}$ Different from other papers which apply perturbation methods directly to the non-linear system of equations, we first approximate the model up to second order and then implement the perturbation method. ${ }^{10}$ Our approach has the advantage that makes it easier to obtain clear analytical results for the link between the level of inflation and oil price volatility.

We write the rational expectations second order solution of output and inflation, in logdeviations from the steady state, as quadratic polynomials in both the level and the standard deviation of oil price shock:

$$
\begin{aligned}
& y_{t}=\frac{1}{2} a_{o} \sigma_{q}^{2}+a_{1} q_{t}+\frac{1}{2} a_{2}\left(q_{t}\right)^{2}+O\left(\left\|q_{t}, \sigma_{q}\right\|^{3}\right) \\
& \pi_{t}=\frac{1}{2} b_{o} \sigma_{q}^{2}+b_{1} q_{t}+\frac{1}{2} b_{2}\left(q_{t}\right)^{2}+O\left(\left\|q_{t}, \sigma_{q}\right\|^{3}\right)
\end{aligned}
$$

where the a's and b's are the unknown coefficients that we need to solve for and $O\left(\left\|q_{t}, \sigma_{q}\right\|^{3}\right)$

\footnotetext{
${ }^{9}$ We implement the perturbation proposed by Schmitt-Grohe and Uribe (2004). This method was originally developed by Judd (1998) and Collard and Julliard (2001). The fixed point algorithm proposed by Collard and Julliard introduces a dependence of the coefficients of the linear and quadratic terms of the solution with the volatility of the shocks. In contrast, the advantage of the algorithm proposed by Schmitt-Grohe and Uribe is that the coefficients of the policy are invariant to the volatility of the shocks and the corresponding ones to the linear part of the solution are the same as those obtained solving a log linear approximated model, which makes both techniques comparable.

${ }^{10}$ Since a second order Taylor expansion is an exact approximation up to second order of any non-linear equation, having the system expressed in this way will give us the same solution as the system in its non-linear form.
} 
denotes terms on $q$ and $\sigma_{q}$ of order equal or higher than three. ${ }^{11}$ Notice that the linear terms $a_{1} q_{t}$ and $b_{1} q_{t}$ correspond to the policy functions that we would obtain using any standard method for linear models (i.e. undetermined coefficients), whereas the additional elements $a_{o}, b_{0}, a_{2}$ and $b_{2}$, account for the effects of second moments. The quadratic terms in the policy function of inflation have two components: $\frac{1}{2} b_{o} \sigma_{q}^{2}$, which is constant and $\frac{1}{2} b_{2}\left(q_{t}\right)^{2}$, which is time varying. Taking the unconditional expectation to equation (5.1) we obtain the level of average inflation as a function of oil price shock volatility and deep parameters

$$
E(\pi)=\frac{1}{2}\left(b_{o}+b_{2}\right) \sigma_{q}^{2}
$$

The perturbation method helps us to recover parameters $b_{o}$ and $b_{2}$, thus allowing us to get an expression for the level of average inflation which reads as follows:

$$
E(\pi)=\frac{1}{2} \frac{1}{\Lambda_{0}}\left[\phi_{y}\left(\Omega_{m c}+\Omega_{\pi}+\Omega_{v}\right)(1+\Psi)+\phi_{y} \omega_{v}+\sigma \kappa_{y} \omega_{y}\right] \sigma_{q}^{2}
$$

where $\Lambda_{0} \equiv\left(\phi_{\pi}-1\right) \kappa_{y}+(1-\beta) \phi_{y}>0$. Equation (5.3) indicates that not only the first moments of oil price affect inflation but also its volatility. According to the above equation, the link between average inflation and oil price volatility depends crucially on how monetary policy is conducted and on the "omegas" coefficients, where the latter are linked to the convexity of both marginal costs and the Phillips curve. In Appendix B.4 we show that the parameter $\Psi$ is positive. Thus, if $\Lambda_{0}>0$, average inflation is always positive, when it holds that

$$
\phi_{y}>-\omega_{y} \sigma \kappa_{y} /\left[\omega_{v}+\left(\Omega_{m c}+\Omega_{\pi}+\Omega_{v}\right)(1+\Psi)\right]>0
$$

since $\omega_{y}$ is negative, the right hand side is positive. In this case, average inflation is increasing on the "omegas" coefficients.

\subsection{The role of monetary policy}

The way the central bank implements its monetary policy plays a crucial role on the positive link between oil price volatility and average inflation. First, a necessary condition for this link to exist is that the central bank rises interest rates in response to output fluctuations, $\phi_{y}>0$. This is so because in this case, a sharp increase in oil prices does not lead the central bank to raise interest rates by so much, implicitly allowing the oil price shock to generate higher and more volatile inflation levels, which, as we described before, generates higher average inflation.

Yet, if the central bank cares only about inflation and does not react to output fluctuations,

\footnotetext{
${ }^{11}$ Schmitt-Grohe and Uribe (2004) show that the quadratic solution does not depend neither on $\sigma_{q}$ nor on $q_{t} \sigma_{q}$. That is, they show that the coefficients in the solution for those terms are zero.
} 
that is $\phi_{y}=0$, the model predicts that average inflation would be negative and small even if oil prices are very volatile. In this case, the oil price shock generates a sharp fall in output triggered by the precautionary savings behavior of households, which more than compensate the impact of oil prices on inflation through a fall in labor costs. This restriction, however is weaken when households do not exhibit precautionary savings, $\omega_{y}=0$. In this case, the link between oil price volatility and average inflation is positive even when, $\phi_{y}=0$. Moreover, as it is shown in Montoro (2010), in this setup it is optimal for the central bank to react both to inflation and output fluctuations, since oil prices generate an endogenous trade-off between stabilizing inflation and the efficient output gap. This endogenous trade off emerges from the combination of a distorted steady state and a CES production function. ${ }^{12}$

Second, there exist an interesting association between the size of average inflation and the well known Taylor principle. Note that the denominator of expression $(5.3), \Lambda_{0}$, is not other thing that the condition that guarantees uniqueness of the rational expectations equilibrium in the canonical new Keynesian model, known as the Taylor principle. To the extent that $\phi_{y}>0$ and above the small threshold needed for having positive average inflation, the larger the reaction to inflation, $\phi_{\pi}$, the larger $\Lambda_{0}$, and consequently the smaller the level of average inflation. While the degree of average inflation is larger when $\phi_{y}$ is larger, this relation weakens when the central bank reacts more aggressively to inflation (larger $\phi_{\pi}$ ). Note also that for small values of $\phi_{\pi}$ there are meaningful differences in the levels of average inflation when changing the reaction to output fluctuations.

A fundamental implication of this analysis is that monetary policy can mitigate the effects of oil price volatility on inflation by reacting more strongly to changes in expected inflation, but at the cost of lower average output. This result reflects the existence of a trade-off between average inflation and average output.

All in all, our exercise shows that a different response of monetary policy could explain different responses of inflation to oil price volatility and, in particular, it could also help to explain why the positive link between oil price volatility and inflation has weaken from 2002 onwards. Clarida, Gali and Gertler (2000) provided evidence of a stronger interest rate response to variations in inflation over the 1990s and 2000s, relative to 1970s. Thus, our analytical framework supports the idea that the improvement of the conduct of monetary policy has played a crucial role in explaining the broken link between oil price volatility and inflation in

\footnotetext{
${ }^{12}$ Benigno and Woodford (2005) in a similar model but without oil price shocks have found an endogenous trade-off by combining a distorted steady state with a government expenditure shock. In their framework, is the combination of a distorted steady state along with a non-linear aggregate budget constraint due to government expenditure crucial for the existence of this endogenous trade-off. Analogous, in our paper, is the combination of the distorted steady state and the non-linearity of the CES production function what delivers the endogenous trade-off.
} 
the more recent period.

\subsection{Some numerical experiments}

In this section we perform some numerical exercises aimed at evaluating the ability of the model to at least qualitatively account for the level of inflation in 2000s. An extensive quantitatively analysis is beyond the scope of the paper, we rather focus on the implication of monetary policy and some properties of oil prices in shifting the link between average inflation an oil prices. In the model, we interpret oil price shocks as the main driven force of inflation, although we are aware that in order to closely match the moments of other macro variables, additional shocks might be necessary.

Table 3 below summarizes the benchmark parameters values. We estimate an oil demand equation for the U.S. to recover both the steady state share of oil prices in marginal costs $(\bar{\alpha}=0.02875)$ and the elasticity of substitution between oil and labor $(\psi=0.02)$. See appendix $\mathrm{C}$ for details on the calculations. ${ }^{13}$ The steady state level of oil price over marginal costs, $\bar{Q} / \overline{M C}$, is set equal to $\bar{\alpha} \cdot{ }^{14}$ We estimate the $\operatorname{AR}(1)$ process for the log of real oil prices during the sample 2002 to 2008. The implied standard deviation of the oil price is equal to $\sigma_{q}=1.49$.

\begin{tabular}{|c|c|c|c|c|c|c|c|c|c|}
\hline \multicolumn{2}{|c|}{ Technology } & \multicolumn{2}{|l|}{ Oil } & \multicolumn{2}{|c|}{ Taylor Rule } & \multicolumn{2}{|c|}{ Preferences } & \multicolumn{2}{|c|}{ Other } \\
\hline $\bar{\alpha}$ & 0.02875 & $\bar{Q} / \overline{M C}$ & 0.02875 & $\varphi_{\pi}$ & 1.54 & $\beta$ & 0.99 & $\theta$ & 0.66 \\
\hline \multirow[t]{2}{*}{$\psi$} & 0.02 & $\rho$ & 0.951 & $\varphi_{y}$ & 0.99 & $\sigma$ & 1 & $\varepsilon$ & 7.88 \\
\hline & & $\sigma_{e}$ & 0.097 & $\varphi_{r}$ & 0.72 & $v$ & 0.5 & & \\
\hline
\end{tabular}

We parameterize the Taylor rule according to Judd-Rudebush (1998). We set a quarterly discount factor, $\beta$, equal to 0.99 which implies an annualized rate of interest of $4 \%$. For the coefficient of risk aversion parameter, $\sigma$, we choose a value of 1 and the inverse of the elasticity of labor supply, $v$, is calibrated to be equal to 0.5 , similar to those values used in the RBC literature. The probability of the Calvo lottery is set equal to 0.66 which implies that firms adjust prices, on average, every three quarters. We choose a degree of monopolistic competition, $\varepsilon$, equal to 7.88 , which implies a firm mark-up of $15 \%$ over the marginal cost.

Table 4 below reports the mean of inflation and output and their corresponding volatilities

\footnotetext{
${ }^{13}$ Other authors considered a larger share of oil in production or costs. For example, Atkeson and Kehoe (1999) use a share of energy in production of 0.043 and Rotemberg and Woodford (1996) a share of energy equal to $5.5 \%$ of the labour costs.

${ }^{14}$ We choose $\bar{Q} / \overline{M C}=\bar{\alpha}$ because we cannot estimate directly $\bar{Q} / \overline{M C}$ and neither we can disentangle the composition of $\bar{\alpha}$ between $\alpha$ and $\bar{Q} / \overline{M C}$. Changing $\bar{Q} / \overline{M C}$ while maintaining constant $\bar{\alpha}$ does barely change the results.
} 
and for comparison we also report the values observed in the data. ${ }^{15}$ The second column of table 4 reports the simulated values under the baseline parameterization. Note that the model delivers a positive level of average inflation similar to that observed in the data ( 0.50 versus 0.57 ) whereas a negative value of output, -0.27 in the model versus -0.20 in the data. Thus, our baseline model does a reasonable job in getting close to the data. The third and fourth columns illustrate the implications of changes in the properties of oil prices over inflation and output. As the third column shows, when the steady-state oil price doubles, average inflation rises more than three times, and average output also declines in similar proportion. Likewise, the fourth column indicates that when oil price volatility increases from 0.1 to 0.4 (four times), average inflation (average output) increases (decreases) above five times compared to the baseline case. These results are consistent with the analytical results and intuition explained in section 5 . Finally, columns 5 and 6 evaluates how average inflation changes when monetary policy varies. Overall the results demonstrate that the way in which monetary policy is conducted is crucial to explain not only the cyclical behavior of inflation and output but also its average levels. Indeed, when $\phi_{\pi}$ rises from 1.2 to 2 average inflation falls by 92 percent where as average output moves from -0.47 to -0.18 . The contrary occurs when $\phi_{y}$ falls. All in all, these results indicate that the more aggressive towards inflation the central banks is, the smaller the impact of oil price volatility over inflation and the larger the impact over output. Thus, the model predicts a policy trade-off in means similar to the traditional trade-off that arises in the log-linear model.

Table 4: Unconditional Moments - Risk Analysis Exercise

\begin{tabular}{lcccccc}
\hline \hline & Data $(2002-2008)$ & Model & $\bar{Q} \uparrow$ & $\sigma_{q} \uparrow$ & $\phi_{\pi}=1.2$ & $\phi_{\pi}=2.0$ \\
Mean Inflation & 0.57 & 0.50 & 1.62 & 2.83 & 2.33 & 0.18 \\
Mean Output & -0.20 & -0.27 & -0.89 & -1.55 & -0.47 & -0.18 \\
S.D. Inflation & 0.30 & 0.91 & 1.80 & 2.30 & 1.44 & 0.60 \\
S.D. Output & 0.98 & 0.47 & 0.93 & 1.23 & 0.44 & 0.53 \\
\hline \hline
\end{tabular}

To illustrate the importance of the different mechanisms that are behind the level of average inflation, table 5 reports the decomposition of average inflation in terms of the "omegas" parameters defined in the previous section. As previously stated, the determinants of average inflation, in general equilibrium, can be de-composed in four components: those arising from the non-linearity (convexity) of the Phillips curve $\left(\Omega_{\pi}\right)$, the non-linearity of the marginal costs $\left(\Omega_{\pi}\right)$, the auxiliary variable $v_{t}\left(\omega_{v}\right.$ and $\left.\Omega_{v}\right)$ and the precautionary savings effect $\left(\omega_{y}\right)$. Worth

\footnotetext{
${ }^{15}$ We use the data from the Haver USECON database (mnemonics are in parentheses). Our measure of the price level is the non-farm business sector deflator (LXNFI), the measure of GDP corresponds to the non-farm business sector output (LXNFO) and our measure of oil prices is the Spot Oil Prices West Texas Intermediate (PZTEXP). We express output in per-capita terms by dividing LXNFO by a measure of civilian non-institutional population aged above $16(\mathrm{LNN})$ and oil prices are deflated by the non-farm business sector deflator.
} 
noting is that the convexity of the marginal cost with respect to oil accounts for 59 percent. Out of this effect, the level of average inflation attributed to price distortions represents about 38 percent. The second determinant in importance is the convexity of the Phillips curve with respect to oil prices accounting for 43 percent of average inflation. Finally, the precautionary savings effect is negative and almost negligible.

Table 5: Average inflation - Effects decomposition (benchmark parameterization)

\begin{tabular}{lcc}
\hline \hline & Average inflation & Percentage \\
\hline Convexity of the Phillips curve $\left(\Omega_{\pi}\right)$ & 0.2164 & 43.6 \\
Marginal costs $\left(\Omega_{m c}\right)$ & 0.2952 & 59.5 \\
Indirect effect: price dispersion & 0.1845 & 38.2 \\
Direct effect: convexity respect to oil prices & 0.1057 & 21.3 \\
Auxiliary variable $v_{t}\left(\omega_{v}\right.$ and $\left.\Omega_{v}\right)$ & -0.00 & -0.3 \\
Precautionary savings $\left(\omega_{y}\right)$ & -0.014 & -2.8 \\
Total & 0.495 & 100.0 \\
\hline \hline
\end{tabular}

\section{Accuracy}

To evaluate the statistical importance of using a second order solution we perform some accuracy analysis. Following Judd (1992) we determine the quality of the solution method defining normalized inflation equation errors. In the model the state variables are given by $s_{t}=\left[q_{t}, \Delta_{t-1}, R_{t-1}\right]$. Then, the solution of a endogenous variable $x_{t}$ in terms of the state variables $s_{t}$ is $x_{t}=x\left(s_{t}\right)$. Because inflation is the variable of interest of the paper, we focus on the residuals of the Phillips curve. We test the accuracy of a transformation of equation (3.16) evaluated at different values of the state variables:

$$
\operatorname{err}(s)=\frac{1}{(\varepsilon-1)} \ln [(1-(1-\theta) \exp ((1-\varepsilon)(n(s)-d(s)))) / \theta]-\pi(s)
$$

If the approximated solution of the model is accurate, then $\operatorname{err}(s)$ should be equal (or close enough) to zero for any value of $s$. The main advantage of considering an expression like (6.1) is that it does not have units and the errors are expressed in terms of inflation. We calculate $\operatorname{err}(s)$ for different values of $s$ using both the linear and quadratic solutions of the model. For comparative purposes we use $\log 10|\operatorname{err}(s)|$, which indicates the number of decimals of the error. The more negative this number the lower the residual and as a result the better the fit of the approximation of the model. 

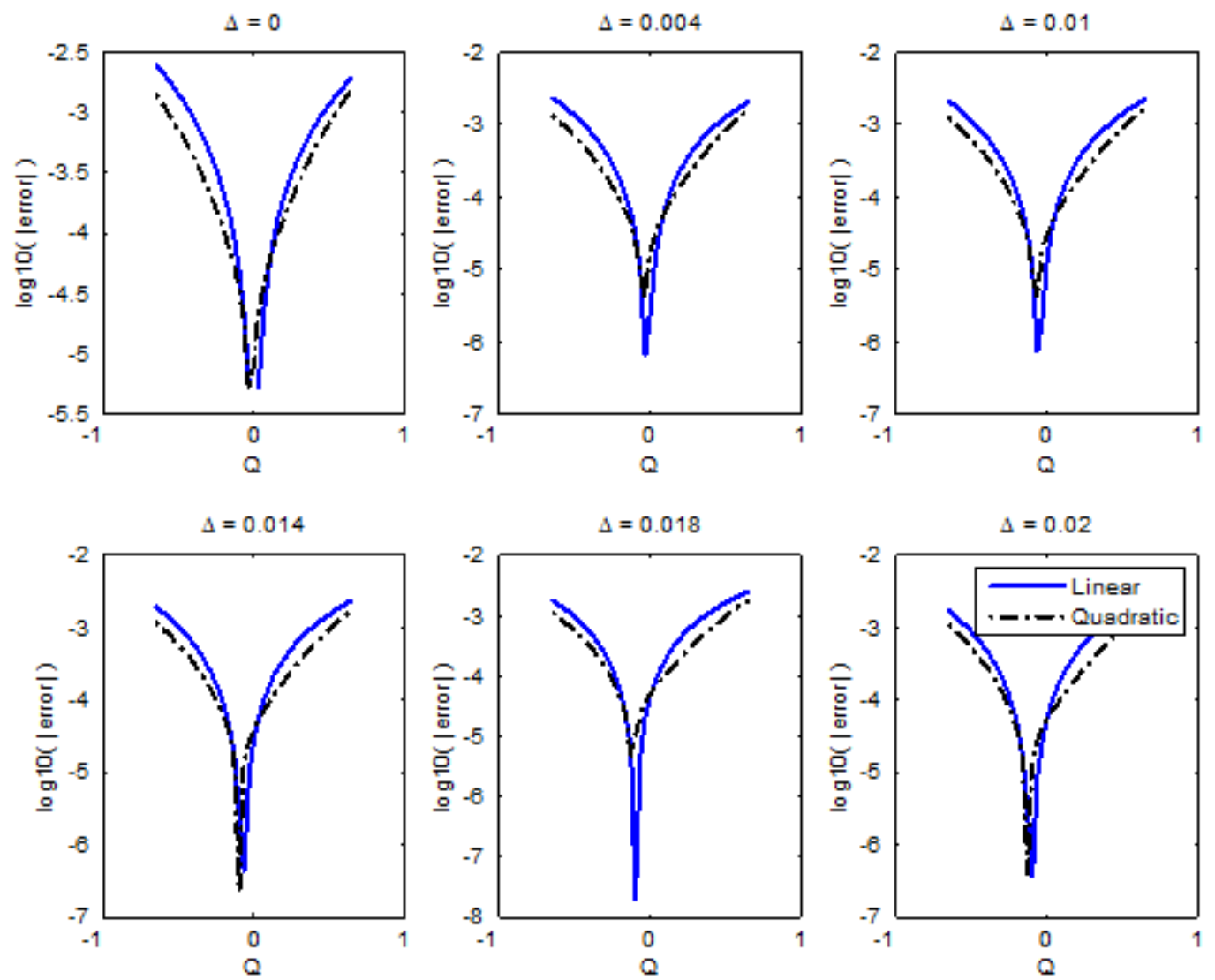

Figure 6.1: Approximation Errors on inflation equation 
Figure 6.1 reproduces the residual term (6.1) on a grid of $q_{t}$ for different values of $\Delta_{t-1}$ and $R_{t-1}$ fixed at 0 . We use the benchmark calibration, where the standard deviation of oil shocks, $\sigma_{\varepsilon}$, is 0.10 . The graph shows that the quadratic solution of the model gives a better fit in terms of inflation when the oil price is away from the steady state. However, the fit with the linear solution is better around the steady state.

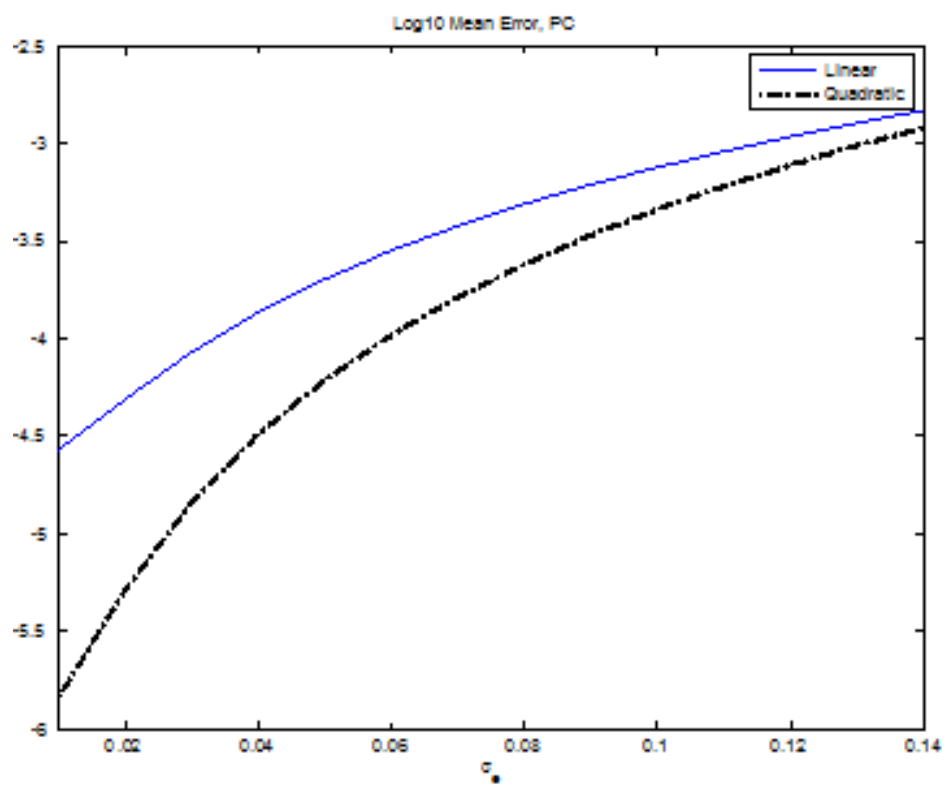

Figure $6.2: \log 10$ mean error of inflation equation

Figure 6.2 plots the mean value of $\log 10|\operatorname{err}(s)|$ for a grid over $s$ as a a global measure of accuracy. We calculate this indicator for different values of the standard deviation of oil price shocks, $\sigma_{\varepsilon}$. Overall, results on accuracy support the second order approximation implemented in the paper to attain the link between average inflation and oil price volatility.

\section{Conclusions}

This paper provides an analytical relationship between oil price volatility and inflation that shows that when the central bank responds to output fluctuations, larger oil price volatility generates higher average inflation. This relationship is stronger when oil has few substitutes and when the convexity of the Phillips curve, the convexity of marginal costs respect to oil and the initial level of relative price dispersion are larger. A fundamental implication of this result is that monetary policy can mitigate the effects of oil price volatility on inflation by reacting 
more strongly to changes in expected inflation, but at the cost of lower average output. This result reflects the existence of a trade-off between average inflation and average output.

Furthermore, the second order solution fully characterizes the role that monetary policy plays in shaping the link between inflation and oil prices. In particular, it illustrates the importance of the Taylor principle to account for the size of average inflation. For rules that are closer to the boundary of indeterminacy determined by the Taylor principle, the solution shows that for the same level of oil price volatility, average inflation is significantly large. Numerical exercises are broadly consistent with the analytical results. In particular, they show that oil price volatility can generate sizeable levels of average inflation, but also that a more conservative monetary policy could mitigate those effects. 


\section{References}

[1] Atkeson, A. and P. Kehoe, 1999. Models of Energy Use: Putty-Putty Versus Putty-Clay. American Economic Review 89, 1028-1043.

[2] Benigno, G. and P. Benigno, 2005. Price Stability in Open Economies. Review of Economic Studies 70, 745-765.

[3] Benigno, P. and M. Woodford, 2003. Optimal Monetary Policy and Fiscal Policy, NBER Macroeconomic Annual, Cambridge, MA: MIT Press.

[4] Benigno, P. and M. Woodford, 2005. Inflation Stabilization and Welfare: The Case of a Distorted Steady State. Journal of the European Economic Association 1, 1-52.

[5] Blanchard, O. and J. Gali, 2007. Real Wage Rigidities and the New Keynesian Model. Journal of Money Credit and Banking 39, 35-66.

[6] Blanchard, O. and J. Gali, 2008. The Macroeconomic Effect of Oil Price Shocks: Why are the 2000s so different from the 1970s?. NBER, International Dimensions of Monetary Policy.

[19] Boragan Aruoba, S., J. Fernandez-Villaverde and J. Rubio-Ramirez, 2006. Comparing soltuion methods for dynamic equilibrium economies, Journal of Economic Dynamics and Control, vol 30(12), 2477-2508.

[8] Calvo, G., 1983. Staggered Prices in a Utility Maximizing Framework. Journal of Monetary Economics 12, 383-398.

[9] Clarida, R, J. Gali, and M. Gertler, 2000. Monetary Policy Rules and Macroeconomic Stability: Evidence and Some Theory. Quarterly Journal of Economics 115, 147-180.

[10] Collard, F. and M. Juillard, 2001. Accuracy of Stochastic Perturbation Methods: The Case of Asset Pricing Models. Journal of Economic Dynamics and Control 25, 979-999.

[11] Evans, M. and V. Hnatkovska, 2005. Solving General Equilibrium Models with Incomplete Markets and Many Assets,NBER Technical Working Paper \#318.

[12] Judd Keneth, 1992. Projection Methods for Solving Aggregate Growth Models. Journal of Economic Theory 58, 410-452.

[13] Judd, K., 1998. Numerical Methods in Economics, MIT, press, Cambridge MA. 
[14] Kim, I-M. and P Loungani, 1992. The Role of Energy in Real Business Cycle Models. Journal of Monetary Economics 20, 173-189.

[15] Montoro, C., 2010. Oil Shocks and Optimal monetary Policy. Forthcoming in Macroeconomic Dynamics.

[16] Obstfeld, M. and K. Rogofff, 1998. Risk and Exchange Rates. NBER 6694.

[17] Rotermberg J. and M. Woodford, 1996. Imperfect Competition and the Effects of Energy Price Increases on Economic Activity. Journal of Money, Credit and Banking 28, 549-577.

[18] Schmitt-Grohe, S. and M. Uribe, 2004. Solving Dynamic General Equilibrium Models Using a Second-order Approximation to the Policy Function. Journal of Economic Dynamics and Control 28, 755-775.

[19] Schmitt-Grohe, S. and M. Uribe, 2005. Optimal inflation stabilization in a medium-scale macroeconomic model. NBER Working Papers $\mathrm{N}^{\circ} 11854$.

[20] Sutherland, A., 2002. A Simple Second-Order Solution Method for Dynamic General Equilibrium Models. CEPR Discussion Paper No 3554, July 2002. 


\section{A Appendix: Equations of the Model}

\section{A.1 The system of equations}

Using the market clearing conditions that close the model, the dynamic equilibrium of the model described in section 3 is given by the following set of 10 equations:

\begin{tabular}{ll}
\hline \hline AGGREGATE SUPPLY & \\
\hline Marginal Costs & \\
$M C_{t}=\left[(1-\alpha)^{\psi}\left(W_{t} / P_{t}\right)^{1-\psi}+\alpha^{\psi}\left(Q_{t}\right)^{1-\psi}\right]^{\frac{1}{1-\psi}}$ & $\mathrm{A}-\mathrm{i}$ \\
Labor market & $\mathrm{A}-\mathrm{ii}$ \\
$\quad \frac{W_{t}}{P_{t}}=Y_{t}^{\sigma} L_{t}^{v}$ & $\mathrm{~A}-\mathrm{iii}$ \\
$L_{t}=\left(\frac{1}{1-\alpha} \frac{W_{t} / P_{t}}{M C_{t}}\right)^{-\psi} Y_{t} \Delta_{t}$ & \\
Price dispersion & $\mathrm{A} 1-\mathrm{iv}$ \\
$\Delta_{t}=(1-\theta)\left(\frac{1-\theta\left(\Pi_{t}\right)^{\varepsilon-1}}{1-\theta}\right)^{\varepsilon /(\varepsilon-1)}+\theta \Delta_{t-1}\left(\Pi_{t}\right)^{\varepsilon}$ & \\
Phillips Curve & $\mathrm{A}-\mathrm{v}$ \\
$\theta\left(\Pi_{t}\right)^{\varepsilon-1}=1-(1-\theta)\left(\frac{N_{t}}{D_{t}}\right)^{1-\varepsilon}$ & $\mathrm{A}-\mathrm{vi}$ \\
$N_{t}=\mu Y_{t}^{1-\sigma} M C_{t}+\theta \beta E_{t}\left(\left(\Pi_{t+1}\right)^{\varepsilon} N_{t+1}\right]$ & $\mathrm{A}-\mathrm{vii}$ \\
$D_{t}=Y_{t}^{1-\sigma}+\theta \beta E_{t}\left[\left(\Pi_{t+1}\right)^{\varepsilon-1} D_{t+1}\right]$ & \\
AGGREGATE DEMAND & $\mathrm{A}-\mathrm{vii}$ \\
\hline $1=\beta E_{t}\left[\left(\frac{Y_{t+1}}{Y_{t}}\right)^{-\sigma} \frac{R_{t}}{\Pi_{t+1}}\right]$ & \\
MONETARY POLICY & $\mathrm{A}-\mathrm{Pix}$ \\
\hline$R_{t}=\bar{R}\left(\frac{E_{t} \Pi_{t+1}}{\bar{\Pi}}\right)^{\phi_{\pi}}\left(\frac{Y_{t}}{\bar{Y}}\right)^{\phi_{y}}$ & $\mathrm{~A}-\mathrm{x}$ \\
\hline OIL PRICES
\end{tabular}

Table A.1: Equations of the model

The first block represents the aggregate supply, which consists on the marginal costs, the labor market equilibrium and the Phillips curve, which has been written recursively using the auxiliary variables $N_{t}$ and $D_{t}$. The aggregate demand block is represented with the Euler equation and Monetary Policy block is given by the Taylor rule. The last equation describes the dynamics of oil prices. We use this set of ten non-linear equations to obtain numerically the second order solution of the model. 


\section{A.2 The deterministic steady state}

The non-stochastic steady state of the endogenous variables is given by: where

\begin{tabular}{ll}
\hline \hline Inflation & $\bar{\Pi}=1$ \\
Auxiliary variables & $\bar{N}=\bar{D}=\bar{Y} /(1-\theta \beta)$ \\
Interest rate & $\bar{R}=\beta^{-1}$ \\
Marginal costs & $\overline{M C}=1 / \mu$ \\
Real wages & $\overline{W / P}=\tau_{y} \frac{1}{\mu}\left(1-\alpha^{F}\right)^{\frac{1}{1-\psi}}$ \\
Output & $\bar{Y}=\tau_{y}\left(\frac{1}{\mu}\right)^{\frac{1}{\sigma+\nu}}\left(1-\alpha^{F}\right)^{\frac{1+\psi \nu}{\sigma+\nu} \frac{1}{1-\psi}}$ \\
Labor & $\bar{L}=\tau_{l}\left(\frac{1}{\mu}\right)^{\frac{1}{\sigma+\nu}}\left(1-\alpha^{F}\right)^{\frac{1-\sigma \psi}{\sigma+\nu} \frac{1}{1-\psi}}$ \\
\hline \hline
\end{tabular}

Table A.2: The steady state

$$
\bar{\alpha}=\alpha^{\psi}\left(\frac{\bar{Q}}{\overline{M C}}\right)^{1-\psi}=\alpha^{\psi}(\mu \bar{Q})^{1-\psi}
$$

$\bar{\alpha}$ is the share of oil in the marginal costs, $\tau_{y}$ and $\tau_{l}$ are constants ${ }^{16}$. Notice that the steady state values of real wages, output and labor depend on the steady state ratio of oil prices with respect to the marginal cost. This implies that permanent changes in oil prices would generate changes in the steady state of this variable. Also, as the standard New-Keynesian models, the marginal cost in steady state is equal to the inverse of the mark-up $(\overline{M C}=1 / \mu=(\varepsilon-1) / \varepsilon)$. Since monopolistic competition affects the steady state of the model, output in steady state is below the efficient level. We call to this feature a distorted steady state.

\section{B Appendix: The second order solution of the model}

\section{B.1 The recursive AS equation}

We divide the equation for the aggregate price level (3.15) by $P_{t}^{1-\varepsilon}$ and make $P_{t} / P_{t-1}=\Pi_{t}$

$$
1=\theta\left(\Pi_{t}\right)^{-(1-\varepsilon)}+(1-\theta)\left(\frac{P_{t}^{*}(z)}{P_{t}}\right)^{1-\varepsilon}
$$

${ }^{16}$ More precisely: $\tau_{y}=\left(\frac{1}{1-\alpha}\right)^{\frac{\psi}{1-\psi} \frac{1+v}{\sigma+v}}$ and $\tau_{l}=\left(\frac{1}{1-\alpha}\right)^{\frac{\psi}{1-\psi} \frac{1-\sigma}{\sigma+v}}$. 
Aggregate inflation is a function of the optimal price level of firm $z$. Also, from equation (3.14) the optimal price of a typical firm can be written as:

$$
\frac{P_{t}^{*}(z)}{P_{t}}=\frac{N_{t}}{D_{t}}
$$

where, after using the definition for the stochastic discount factor: $\zeta_{t, t+k}=\beta C_{t+k}^{-\sigma} / C_{t}^{-\sigma} P_{t} / P_{t+k}$, we define $N_{t}$ and $D_{t}$ as follows:

$$
\begin{aligned}
& N_{t}=E_{t}\left[\sum_{k=0}^{\infty} \mu(\theta \beta)^{k+1} F_{t, t+k}^{\varepsilon} Y_{t+k} C_{t+k}^{-\sigma} M C_{t+k}\right] \\
& D_{t}=E_{t}\left[\sum_{k=0}^{\infty}(\theta \beta)^{k+1} F_{t, t+k}^{\varepsilon-1} Y_{t+k} C_{t+k}^{-\sigma}\right]
\end{aligned}
$$

$N_{t}$ and $D_{t}$ can be expanded as:

$$
\begin{aligned}
& N_{t}=\mu Y_{t} C_{t}^{-\sigma} M C_{t}+E_{t}\left[\Pi_{t+1}^{\varepsilon} \sum_{k=0}^{\infty} \mu(\theta \beta)^{k} F_{t+1, t+1+k}^{\varepsilon} Y_{t+1+k} C_{t+1+k}^{-\sigma} M C_{t+1+k}\right] \\
& D_{t}=Y_{t} C_{t}^{-\sigma}+E_{t}\left[\Pi_{t+1}^{\varepsilon-1} \sum_{k=0}^{\infty}(\theta \beta)^{k} F_{t+1, t+1+k}^{\varepsilon-1} C_{t+1+k}^{-\sigma} Y_{t+1+k}\right]
\end{aligned}
$$

where we have used the definition for $F_{t, t+k}=P_{t+k} / P_{t}$.

The Phillips curve with oil prices is given by the following three equations:

$$
\begin{gathered}
\theta\left(\Pi_{t}\right)^{\varepsilon-1}=1-(1-\theta)\left(\frac{P_{t}^{*}(z)}{P_{t}}\right)^{1-\varepsilon} \\
N_{t}=\mu Y_{t}^{1-\sigma} M C_{t}+\theta \beta E_{t}\left(\Pi_{t+1}\right)^{\varepsilon} N_{t+1} \\
D_{t}=Y_{t}^{1-\sigma}+\theta \beta E_{t}\left(\Pi_{t+1}\right)^{\varepsilon-1} D_{t+1}
\end{gathered}
$$

where we have reordered equation (B.1) and we have used equations (B.2) and (B.3) evaluated one period forward to replace $N_{t+1}$ and $D_{t+1}$ in equations (B.4) and (B.5). 


\section{B.2 The second order approximation of the system}

\section{B.2.1 The second order approximation of the Phillips Curve}

The second order expansion for equations $(B .6),(B .7)$ and $(B .8)$ are:

$$
\begin{gathered}
\pi_{t}=\frac{(1-\theta)}{\theta}\left(n_{t}-d_{t}\right)-\frac{1}{2} \frac{(\varepsilon-1)}{1-\theta}\left(\pi_{t}\right)^{2}+O\left(\left\|q_{t}, \sigma_{q}\right\|^{3}\right) \\
n_{t}=(1-\theta \beta)\left(a_{t}+\frac{1}{2} a_{t}^{2}\right)+\theta \beta\left(E_{t} b_{t+1}+\frac{1}{2} E_{t} b_{t+1}^{2}\right)-\frac{1}{2} n_{t}^{2}+O\left(\left\|q_{t}, \sigma_{q}\right\|^{3}\right) \\
d_{t}=(1-\theta \beta)\left(c_{t}+\frac{1}{2} c_{t}^{2}\right)+\theta \beta\left(E_{t} e_{t+1}+\frac{1}{2} E_{t} e_{t+1}^{2}\right)-\frac{1}{2} d_{t}^{2}+O\left(\left\|q_{t}, \sigma_{q}\right\|^{3}\right)
\end{gathered}
$$

Where we have defined the auxiliary variables $a_{t}, b_{t+1}, c_{t}$ and $e_{t+1}$ as:

$$
\begin{array}{cc}
a_{t} \equiv(1-\sigma) y_{t}+m c_{t} & b_{t+1} \equiv \varepsilon \pi_{t+1}+n_{t+1} \\
c_{t} \equiv(1-\sigma) y_{t} & e_{t+1} \equiv(\varepsilon-1) \pi_{t+1}+d_{t+1}
\end{array}
$$

Subtract equations $(B .10)$ and $(B .11)$, and using the fact that $X^{2}-Y^{2}=(X-Y)(X+Y)$, for any two variables $X$ and $Y$ :

$$
\begin{aligned}
n_{t}-d_{t}= & (1-\theta \beta)\left(a_{t}-c_{t}\right)+\frac{1}{2}(1-\theta \beta)\left(a_{t}-c_{t}\right)\left(a_{t}+c_{t}\right) \\
& +\theta \beta E_{t}\left(b_{t+1}-e_{t+1}\right)+\frac{1}{2} \theta \beta E_{t}\left(b_{t+1}-e_{t+1}\right)\left(b_{t+1}+e_{t+1}\right) \\
& -\frac{1}{2}\left(n_{t}-d_{t}\right)\left(n_{t}+d_{t}\right)+O\left(\left\|q_{t}, \sigma_{q}\right\|^{3}\right)
\end{aligned}
$$

Plugging in the values of $a_{t}, b_{t+1}, c_{t}$ and $e_{t+1}$ into equation (B.12), we obtain (B.13)

$$
\begin{aligned}
n_{t}-d_{t}= & (1-\theta \beta) m c_{t}+\frac{1}{2}(1-\theta \beta) m c_{t}\left(2(1-\sigma) y_{t}+m c_{t}\right) \\
& +\theta \beta E_{t}\left(\pi_{t+1}+n_{t+1}-d_{t+1}\right)+\frac{1}{2} \theta \beta E_{t}\left(\pi_{t+1}+n_{t+1}-d_{t+1}\right)\left((2 \varepsilon-1) \pi_{t+1}+n_{t+1}+d_{t+1}\right) \\
& -\frac{1}{2}\left(n_{t}-d_{t}\right)\left(n_{t}+d_{t}\right)+O\left(\left\|q_{t}, \sigma_{q}\right\|^{3}\right)
\end{aligned}
$$

Taking forward one period equation (B.9), we can solve for $n_{t+1}-d_{t+1}$ :

$$
n_{t+1}-d_{t+1}=\frac{\theta}{1-\theta} \pi_{t+1}+\frac{1}{2} \frac{\theta}{1-\theta} \frac{(\varepsilon-1)}{1-\theta}\left(\pi_{t+1}\right)^{2}+O\left(\left\|q_{t}, \sigma_{q}\right\|^{3}\right)
$$


replace equation $(B .14)$ in $(B .13)$ and make use of the auxiliary variable $z_{t}=\left(n_{t}+d_{t}\right) /(1-\theta \beta)$

$$
\begin{aligned}
n_{t}-d_{t}= & (1-\theta \beta) m c_{t}+\frac{1}{2}(1-\theta \beta) m c_{t}\left(2(1-\sigma) y_{t}+m c_{t}\right) \\
& +\frac{\theta}{1-\theta} \beta\left[E_{t} \pi_{t+1}+\left(\frac{\varepsilon-1}{1-\theta}+\varepsilon\right) E_{t} \pi_{t+1}^{2}+(1-\theta \beta) E_{t} \pi_{t+1} z_{t+1}\right] \\
& -\frac{1}{2} \frac{\theta}{1-\theta}(1-\theta \beta) \pi_{t} z_{t}+O\left(\left\|q_{t}, \sigma_{q}\right\|^{3}\right)
\end{aligned}
$$

Notice that we use only the linear part of equation $(B .14)$ when we replace $n_{t+1}-d_{t+1}$ in the quadratic terms because we are interested in capture terms only up to second order of accuracy. Similarly, we make use of the linear part of equation (B.9) to replace $\left(n_{t}-d_{t}\right)=\frac{\theta}{1-\theta} \pi_{t}$ in the right hand side of equation (B.15).

Replace equation $(B .15)$ in $(B .9)$ :

$$
\begin{aligned}
\pi_{t}= & \kappa m c_{t}+\frac{1}{2} \kappa m c_{t}\left(2(1-\sigma) y_{t}+m c_{t}\right) \\
& +\beta\left[E_{t} \pi_{t+1}+\left(\frac{\varepsilon-1}{1-\theta}+\varepsilon\right) E_{t} \pi_{t+1}^{2}+(1-\theta \beta) E_{t} \pi_{t+1} z_{t+1}\right] \\
& -\frac{1}{2}(1-\theta \beta) \pi_{t} z_{t}-\frac{1}{2} \frac{(\varepsilon-1)}{1-\theta}\left(\pi_{t}\right)^{2}+O\left(\left\|q_{t}, \sigma_{q}\right\|^{3}\right)
\end{aligned}
$$

for

$$
\kappa \equiv \frac{(1-\theta)}{\theta}(1-\theta \beta)
$$

where $z_{t}$ has the following linear expansion:

$$
z_{t}=2(1-\sigma) y_{t}+m c_{t}+\theta \beta E_{t}\left(\frac{2 \varepsilon-1}{1-\theta \beta} \pi_{t+1}+z_{t+1}\right)+O\left(\left\|q_{t}, \sigma_{q}\right\|^{2}\right)
$$

Define the following auxiliary variable:

$$
v_{t}=\pi_{t}+\frac{1}{2}\left(\frac{\varepsilon-1}{1-\theta}+\varepsilon\right) \pi_{t}^{2}+\frac{1}{2}(1-\theta \beta) \pi_{t} z_{t}
$$

Using the definition for $v_{t}$, equation $(B .16)$ can be expressed as:

$$
v_{t}=\kappa m c_{t}+\frac{1}{2} \kappa m c_{t}\left(2(1-\sigma) y_{t}+m c_{t}\right)+\frac{1}{2} \varepsilon \pi_{t}^{2}+\beta E_{t} v_{t+1}+O\left(\left\|q_{t}, \sigma_{q}\right\|^{2}\right)
$$

which is equation (4.3) in the main text.

Moreover, the linear part of equation (B.19) is:

$$
\pi_{t}=\kappa m c_{t}+\beta E_{t}\left(\pi_{t+1}\right)+O\left(\left\|q_{t}, \sigma_{q}\right\|^{2}\right)
$$


which is the standard New Keynesian Phillips curve, inflation depends linearly on the real marginal costs and expected inflation.

\section{B.2.2 The MC equation and the labor market equilibrium}

The real marginal cost (3.12) and the labor market equations (3.4 and 3.22) have the following second order expansion:

$$
\begin{gathered}
m c_{t}=(1-\bar{\alpha}) w_{t}+\bar{\alpha} q_{t}+\frac{1}{2} \bar{\alpha}(1-\bar{\alpha})(1-\psi)\left(w_{t}-q_{t}\right)^{2}+O\left(\left\|q_{t}, \sigma_{q}\right\|^{3}\right) \\
w_{t}=\nu l_{t}+\sigma y_{t} \\
l_{t}=y_{t}-\psi\left(w_{t}-m c_{t}\right)+\widehat{\Delta}_{t}
\end{gathered}
$$

Where $w_{t}$ and $\widehat{\Delta}_{t}$ are, respectively, the log of the deviation of the real wage and the price dispersion measure from their respective steady state. Notice that equations (B.21)and (B.22) are not approximations, but exact expressions.

Solving equations (B.21) and (B.22) for the equilibrium real wage:

$$
w_{t}=\frac{1}{1+\nu \psi}\left[(\nu+\sigma) y_{t}+\nu \psi m c_{t}+v \widehat{\Delta}_{t}\right]
$$

Plugging the real wage in equation (B.20) and simplifying:

$$
\begin{aligned}
m c_{t}= & \chi(\sigma+v) y_{t}+(1-\chi)\left(q_{t}\right)+\chi v \widehat{\Delta}_{t} \\
& +\frac{1}{2} \frac{1-\psi}{1-\bar{\alpha}} \chi^{2}(1-\chi)\left[(\sigma+v) y_{t}-q_{t}\right]^{2}+O\left(\left\|q_{t}, \sigma_{q}\right\|^{3}\right)
\end{aligned}
$$

where $\chi \equiv(1-\bar{\alpha}) /(1+v \psi \bar{\alpha})$. This is the equation $(i)$ in the main text. This expression is the second order expansion of the real marginal cost as a function of output and the oil prices.

\section{B.2.3 The price dispersion measure}

The price dispersion measure is given by

$$
\Delta_{t}=\int_{0}^{1}\left(\frac{P_{t}(z)}{P_{t}}\right)^{-\varepsilon} d z
$$


Since a proportion $1-\theta$ of intermediate firms set prices optimally, whereas the other $\theta$ set the price last period, this price dispersion measure can be written as:

$$
\Delta_{t}=(1-\theta)\left(\frac{P_{t}^{*}(z)}{P_{t}}\right)^{-\varepsilon}+\theta \int_{0}^{1}\left(\frac{P_{t-1}(z)}{P_{t}}\right)^{-\varepsilon} d z
$$

Dividing and multiplying by $\left(P_{t-1}\right)^{-\varepsilon}$ the last term of the RHS:

$$
\Delta_{t}=(1-\theta)\left(\frac{P_{t}^{*}(z)}{P_{t}}\right)^{-\varepsilon}+\theta \int_{0}^{1}\left(\frac{P_{t-1}(z)}{P_{t-1}}\right)^{-\varepsilon}\left(\frac{P_{t-1}}{P_{t}}\right)^{-\varepsilon} d z
$$

Since $P_{t}^{*}(z) / P_{t}=N_{t} / D_{t}$ and $P_{t} / P_{t-1}=\Pi_{t}$, using equation (3.8) in the text and the definition for the dispersion measure lagged on period, this can be expressed as

$$
\Delta_{t}=(1-\theta)\left(\frac{1-\theta\left(\Pi_{t}\right)^{\varepsilon-1}}{1-\theta}\right)^{\varepsilon /(\varepsilon-1)}+\theta \Delta_{t-1}\left(\Pi_{t}\right)^{\varepsilon}
$$

which is a recursive representation of $\Delta_{t}$ as a function of $\Delta_{t-1}$ and $\Pi_{t}$.

Benigno and Woodford (2005) show that a second order approximation of the price dispersion depends solely on second order terms on inflation. Then, the second order approximation of equation (B.25) is:

$$
\widehat{\Delta}_{t}=\theta \widehat{\Delta}_{t-1}+\frac{1}{2} \varepsilon \frac{\theta}{1-\theta} \pi_{t}^{2}+O\left(\left\|q_{t}, \sigma_{q}\right\|^{3}\right)
$$

which is equation $(2-i i)$ in the main text. Moreover, we use equation (B.26) to write the infinite sum:

$$
\begin{aligned}
\sum_{t=t_{o}}^{\infty} \beta^{t-t_{o}} \widehat{\Delta}_{t} & =\theta \sum_{t=t_{o}}^{\infty} \beta^{t-t_{o}} \widehat{\Delta}_{t-1}+\frac{1}{2} \varepsilon \frac{\theta}{1-\theta} \sum_{t=t_{o}}^{\infty} \beta^{t-t_{o}} \frac{\pi_{t}^{2}}{2}+O\left(\left\|q_{t}, \sigma_{q}\right\|^{3}\right) \\
(1-\beta \theta) \sum_{t=t_{o}}^{\infty} \beta^{t-t_{o}} \widehat{\Delta}_{t} & =\theta \widehat{\Delta}_{t_{o}-1}+\frac{1}{2} \varepsilon \frac{\theta}{1-\theta} \sum_{t=t_{o}}^{\infty} \beta^{t-t_{o}} \frac{\pi_{t}^{2}}{2}+O\left(\left\|q_{t}, \sigma_{q}\right\|^{3}\right)
\end{aligned}
$$

Dividing by $(1-\beta \theta)$ and using the definition of $\kappa$ :

$$
\sum_{t=t_{o}}^{\infty} \beta^{t-t_{o}} \widehat{\Delta}_{t}=\frac{\theta}{1-\beta \theta} \widehat{\Delta}_{t_{o}-1}+\frac{1}{2} \frac{\varepsilon}{\kappa} \sum_{t=t_{o}}^{\infty} \beta^{t-t_{o}} \frac{\pi_{t}^{2}}{2}+O\left(\left\|q_{t}, \sigma_{q}\right\|^{3}\right)
$$

The discounted infinite sum of $\widehat{\Delta}_{t}$ is equal to the sum of two terms, on the initial price dispersion and the discounted infinite sum of $\pi_{t}^{2}$. 


\section{B.2.4 The IS}

Similarly, the second order expansion of the IS is:

$$
y_{t}=E_{t} y_{t+1}-\frac{1}{\sigma}\left(r_{t}-E_{t} \pi_{t+1}\right)-\frac{1}{2} \sigma E_{t}\left[\left(y_{t}-y_{t+1}\right)-\frac{1}{\sigma}\left(r_{t}-\pi_{t+1}\right)\right]^{2}+\left(\left\|q_{t}, \sigma_{q}\right\|^{3}\right)
$$

Replacing the linear solution of $y_{t}$ inside the quadratic part of equation (B.28):

$$
y_{t}=E_{t} y_{t+1}-\frac{1}{\sigma}\left(r_{t}-E_{t} \pi_{t+1}\right)-\frac{1}{2} \sigma E_{t}\left[y_{t+1}+\frac{1}{\sigma} \pi_{t+1}-E_{t}\left(y_{t+1}+\frac{1}{\sigma} \pi_{t+1}\right)\right]^{2}+\left(\left\|q_{t}, \sigma_{q}\right\|^{3}\right)
$$

where $E_{t}\left[y_{t+1}+\frac{1}{\sigma} \pi_{t+1}-E_{t}\left(y_{t+1}+\frac{1}{\sigma} \pi_{t+1}\right)\right]^{2}$ is the variance of $\left(y_{t+1}+\frac{1}{\sigma} \pi_{t+1}\right)$. 


\section{B.3 The system in two equations}

Since the quadratic terms of the second order Taylor expansions of the equations depend on the linear solution, we can use the latter to solve for the formers. Let's assume the linear solution for output, inflation and the auxiliary variable $z_{t}{ }^{17}$

$$
\begin{aligned}
& y_{t}=a_{1} q_{t}+O\left(\left\|q_{t}, \sigma_{q}\right\|^{2}\right) \\
& \pi_{t}=b_{1} q_{t}+O\left(\left\|q_{t}, \sigma_{q}\right\|^{2}\right) \\
& z_{t}=c_{1} q_{t}+O\left(\left\|q_{t}, \sigma_{q}\right\|^{2}\right)
\end{aligned}
$$

Additionally, we have the transition process for the oil price:

$$
q_{t}=\rho q_{t-1}+\eta \sigma_{q} e_{t}
$$

where $e^{\sim} i i d(0,1)$ and $\eta=\sqrt{1-\rho^{2}}$.

\section{B.3.1 The AS}

Replacing the equation for the price dispersion in the equation for the marginal costs, the latter can be expressed as:

$$
m c_{t}=\chi(v+\sigma) y_{t}+(1-\chi) q_{t}+\chi v \widehat{\Delta}_{t}+\frac{1}{2} \widetilde{\Omega}_{m c} q_{t}^{2}+O\left(\left\|q_{t}, \sigma_{q}\right\|^{3}\right)
$$

where $\widetilde{\Omega}_{m c}=(1-\chi) \chi^{2} \frac{1-\psi}{1-\bar{\alpha}}\left((\nu+\sigma) a_{1}-1\right)^{2}+\varepsilon \frac{\theta}{1-\theta}\left(b_{1}\right)^{2}$.

Similarly, the Phillips curve equation can be expressed as:

$$
v_{t}=\kappa m c_{t}+\beta E_{t} v_{t+1}+\frac{1}{2} \Omega_{\pi} q_{t}^{2}+O\left(\left\|q_{t}, \sigma_{q}\right\|^{3}\right)
$$

where $\Omega_{\pi}=\varepsilon\left(b_{1}\right)^{2}+\kappa\left[\chi(v+\sigma) a_{1}+(1-\chi)\right]\left[2(1-\sigma) y_{t}+\chi(v+\sigma) a_{1}+(1-\chi)\right]$. We have used the linear solution of output and inflation to express $\Omega_{\pi}$ in terms of $a_{1}$ and $b_{1}$.

Replace the equation for the marginal costs in the second order expansion of the Phillips Curve and iterate forward, the Phillips curve can be expressed as the discounted infinite sum:

$$
v_{t}=\sum_{t=t_{o}}^{\infty} \beta^{t-t_{o}}\left\{\kappa_{y} y_{t}+\kappa_{q} q_{t}+\kappa \chi v \widehat{\Delta}_{t}+\frac{1}{2} \kappa \widetilde{\Omega}_{m c} q_{t}^{2}+\frac{1}{2} \Omega_{\pi} q_{t}^{2}\right\}+\left(\left\|q_{t}, \sigma_{q}\right\|^{3}\right)
$$

${ }^{17}$ From the linear expansion of the definition of $z_{t}$ we can solve for $c_{1}$, where $c_{1}=$ $\frac{1}{1-\theta \beta \rho}\left\{[2(1-\sigma)+\chi(\sigma+v)] a_{1}+(1-\chi)+\theta \beta \frac{2 \varepsilon-1}{1-\theta \beta} \rho b_{1}\right\}$ 
where $\kappa_{y}=\kappa \chi(\sigma+\nu)$ and $\kappa_{q}=\kappa(1-\chi)$. Make use of equation (B.27), the discounted infinite sum of $\widehat{\Delta}_{t}, v_{t}$ becomes:

$$
\begin{aligned}
v_{t}= & \sum_{t=t_{o}}^{\infty} \beta^{t-t_{o}}\left\{\kappa_{y} y_{t}+\kappa_{q} q_{t}+\frac{1}{2} \varepsilon \chi v \pi_{t}^{2}+\frac{1}{2} \kappa \widetilde{\Omega}_{m c} q_{t}^{2}+\frac{1}{2} \Omega_{\pi} q_{t}^{2}\right\} \\
& +\frac{\kappa \chi v \theta}{1-\beta \theta} \widehat{\Delta}_{t-1}+\left(\left\|q_{t}, \sigma_{q}\right\|^{3}\right)
\end{aligned}
$$

Assuming that we depart from an initial state where the price dispersion is small, that is $\widehat{\Delta}_{t-1} \simeq 0$ up to second order, then equation (B.33) can be expressed recursively as ${ }^{18}$ :

$$
v_{t}=\kappa_{y} y_{t}+\kappa_{q} q_{t}+\frac{1}{2} \varepsilon \chi v \pi_{t}^{2}+\frac{1}{2} \kappa \widetilde{\Omega}_{m c} q_{t}^{2}+\frac{1}{2} \Omega_{\pi} q_{t}^{2}+\beta E_{t} v_{t+1}+\left(\left\|q_{t}, \sigma_{q}\right\|^{3}\right)
$$

Let's consider the total second order terms coming from the marginal costs:

$$
\Omega_{m c} q_{t}^{2}=\varepsilon \chi v \pi_{t}^{2}+\kappa \widetilde{\Omega}_{m c} q_{t}^{2}
$$

then, $\Omega_{m c}=\varepsilon \chi v\left(b_{1}\right)^{2}+\kappa \widetilde{\Omega}_{m c}$.

The auxiliary variable $v_{t}$ is also affected by second order terms:

$$
v_{t}=\pi_{t}+\frac{1}{2} \widetilde{\Omega}_{v} q_{t}^{2}
$$

where $\widetilde{\Omega}_{v}=\left[\left(\frac{\varepsilon-1}{1-\theta}+\varepsilon\right) b_{1}^{2}+(1-\theta \beta) b_{1} c_{1}\right] \cdot E_{t} v_{t+1}$ becomes:

$$
\begin{aligned}
E_{t} v_{t+1} & =E_{t} \pi_{t+1}+\frac{1}{2} \widetilde{\Omega}_{v} E_{t} q_{t+1}^{2} \\
& =E_{t} \pi_{t+1}+\frac{1}{2} \widetilde{\Omega}_{v}\left(\rho^{2} q_{t}^{2}+\eta^{2} \sigma_{q}^{2}\right)
\end{aligned}
$$

Replacing equations (B.35), (B.36) and (B.37) in (B.34), we obtain the equation (4.1) in the text:

$$
\pi_{t}=\kappa_{y} y_{t}+\kappa_{q} q_{t}+\beta E_{t} \pi_{t+1}+\frac{1}{2}\left(\Omega_{m c}+\Omega_{\pi}+\Omega_{v}\right) q_{t}^{2}+\frac{1}{2} \omega_{v} \sigma_{q}^{2}+\left(\left\|q_{t}, \sigma_{q}\right\|^{3}\right)
$$

where $\Omega_{v}=-\widetilde{\Omega}_{v}\left(1-\beta \rho^{2}\right)$ and $\omega_{v}=\widetilde{\omega}_{v} \beta \eta^{2} . \Omega_{m c}, \Omega_{\pi}, \Omega_{v}$ and $\omega_{v}$ are respectively the second order terms coming from the marginal costs, the Phillips Curve and the auxiliary variable $v_{t}$.

${ }^{18}$ We make the assumption that the initial price dispersion is small to make the analysis analytically tractable. However, in the numerical exercise we work with the general case and the results are quantitatively similar. 


\section{B.3.2 The aggregate demand}

Replace the policy rule in the second order expansion of the IS (B.29), assuming there is not interest rate smoothing (that is $\phi_{r}=0$ ) :

$$
\begin{aligned}
y_{t}= & E_{t} y_{t+1}-\frac{1}{\sigma}\left[\left(\phi_{\pi}-1\right) E_{t} \pi_{t+1}+\phi_{y} y_{t}\right]+ \\
& -\frac{1}{2} \sigma E_{t}\left[y_{t+1}+\frac{1}{\sigma} \pi_{t+1}-E_{t}\left(y_{t+1}+\frac{1}{\sigma} \pi_{t+1}\right)\right]^{2}+O\left(\left\|q_{t}, \sigma_{q}\right\|^{3}\right)
\end{aligned}
$$

This can be expressed as:

$$
y_{t}=E_{t}\left(y_{t+1}\right)-\frac{1}{\sigma}\left[\left(\phi_{\pi}-1\right) E_{t} \pi_{t+1}+\phi_{y} y_{t}\right]+\frac{1}{2} \omega_{y} \sigma_{q}^{2}+O\left(\left\|q_{t}, \sigma_{q}\right\|^{3}\right)
$$

where:

$$
\omega_{y} \sigma_{q}^{2}=-\sigma E_{t}\left[a_{1} q_{t+1}+\frac{1}{\sigma} b_{1} q_{t+1}-E_{t}\left(a_{1} q_{t+1}+\frac{1}{\sigma} b_{1} q_{t+1}\right)\right]^{2}
$$

Similar to the previous sub-section, the IS risk premium can be written as a function of the linear solution of inflation and output:

$$
\omega_{y}=-\sigma\left(a_{1}+\frac{1}{\sigma} b_{1}\right)^{2}<0
$$

Note that the risk premium component of the IS is negative, capturing precautionary savings due to output and inflation volatility.

\section{B.4 The perturbation method}

The policy functions of the second order solution for output and inflation can be written in the following form:

$$
\begin{aligned}
& y_{t}=\frac{1}{2} a_{o} \sigma_{q}^{2}+a_{1} q_{t}+\frac{1}{2} a_{2}\left(q_{t}\right)^{2}+O\left(\left\|q_{t}, \sigma_{q}\right\|^{3}\right) \\
& \pi_{t}=\frac{1}{2} b_{o} \sigma_{q}^{2}+b_{1} q_{t}+\frac{1}{2} b_{2}\left(q_{t}\right)^{2}+O\left(\left\|q_{t}, \sigma_{q}\right\|^{3}\right)
\end{aligned}
$$

where the $a^{\prime} s$ and $b^{\prime} s$ are the unknown coefficients that we need to solve for and $O\left(\left\|q_{t}, \sigma_{q}\right\|^{3}\right)$ denotes terms on $q$ and $\sigma_{q}$ of order equal or higher than 3. We express the dynamics of the oil price as:

$$
q_{t}=\rho q_{t-1}+\eta \sigma_{q} e_{t}
$$


where the oil shock has been normalized to have mean zero and standard deviation of one, i.e. $e^{\sim} i i d(0,1)$.Also, we set $\eta=\sqrt{1-\rho^{2}}$ in order to express $V\left(q_{t}\right)=\sigma_{q}^{2}$.

In order to solve for the 6 unknown coefficients, we use the following algorithm that consist in solving recursively for three systems of two equations. This allows us to obtain algebraic solutions for the unknown coefficients. We follow the following steps:

1. We replace the closed forms of the policy functions (B.43) and the transition equation for the shock (B.44) in the equations for the AS (B.38) and the AD (B.40).

2. Solve for $a_{1}$ and $b_{1}$ : we take the partial derivatives with respect to $q_{t}$ to the two equations of step 1 , then we proceed to evaluate them in the non-stochastic steady state (i.e. when $q_{t}=0$ and $\left.\sigma_{q}=0\right)$. Then, the only unknowns left are $a_{1}$ and $b_{1}$ for two equations. We proceed to solve for $a_{1}$ and $b_{1}$ as function of the deep parameters of the model.

$$
\begin{aligned}
& a_{1}=-\left[\left(\phi_{\pi}-1\right) \rho\right] \kappa_{q} \frac{1}{\Lambda_{1}}<0 \\
& b_{1}=\left[\sigma(1-\rho)+\phi_{y}\right] \kappa_{q} \frac{1}{\Lambda_{1}}>0
\end{aligned}
$$

3. Solve for $a_{2}$ and $b_{2}$ : similar to step 2, we take successive partial derivatives with respect to $q_{t}$ and $q_{t}$ to the two equations of step 1 and we evaluate them at the non-stochastic steady state. Then, we solve for the unknowns $a_{2}$ and $b_{2}$.

$$
\begin{aligned}
& a_{2}=-\left[\left(\phi_{\pi}-1\right) \rho^{2}\right]\left(\Omega_{\pi}+\Omega_{m c}\right) \frac{1}{\Lambda_{2}}<0 \\
& b_{2}=\left[\sigma\left(1-\rho^{2}\right)+\phi_{y}\right]\left(\Omega_{\pi}+\Omega_{m c}\right) \frac{1}{\Lambda_{2}}>0
\end{aligned}
$$

4. Solve for $a_{0}$ and $b_{0}$ : similar to steps 2 and 3, we take successive partial derivatives with respect to $\sigma_{q}$ and $\sigma_{q}$ to the two equations of step 1 and we evaluate them at the nonstochastic steady state. Then, we solve for the unknowns $a_{0}$ and $b_{0}$. The solution for the coefficients is given by:

$$
\begin{aligned}
a_{o} & =-\left(\phi_{\pi}-1\right)\left[\left(b_{2} \eta^{2}+\omega_{\pi}\right)-\sigma(1-\beta)\left(a_{2} \eta^{2}+\omega_{y}\right)\right] \frac{1}{\Lambda_{0}} \\
b_{o} & =-b_{2} \eta^{2}+\left[\phi_{y}\left(b_{2} \eta^{2}+\omega_{\pi}\right)+\sigma \kappa_{y}\left(a_{2} \eta^{2}+\omega_{y}\right)\right] \frac{1}{\Lambda_{0}}
\end{aligned}
$$


where we have defined the following auxiliary variables:

$$
\begin{gathered}
\Lambda_{0}=\left(\phi_{\pi}-1\right) \kappa_{1}+(1-\beta) \phi_{y} \\
\Lambda_{1}=\left(\phi_{\pi}-1\right) \rho \kappa_{y}+(1-\beta \rho)\left[\sigma(1-\rho)+\phi_{y}\right] \\
\Lambda_{2}=\left(\phi_{\pi}-1\right) \rho^{2} \kappa_{y}+\left(1-\beta \rho^{2}\right)\left[\sigma(1-\rho)^{2}+\phi_{y}\right]
\end{gathered}
$$

where $\Lambda_{0}, \Lambda_{1}$, and $\Lambda_{2}$ are all positive.

\section{B.4.1 The Inflation premium}

The inflation premium is given by:

$$
E(\pi)=\frac{1}{2}\left(b_{o}+b_{2}\right) \sigma_{q}^{2}
$$

replace the solution for $b_{o}$ :

$$
b_{o}+b_{2}=b_{2} \rho^{2}+\frac{\phi_{y}\left(b_{2} \eta^{2}+\omega_{\pi}\right)+\sigma \kappa_{y}\left(a_{2} \eta^{2}+\omega_{y}\right)}{\Lambda_{0}}
$$

Replace the solution of $a_{2}$ and the definition of $\eta$, and collect for $b_{2}$ :

$$
b_{o}+b_{2}=\frac{1}{\Lambda_{0}}\left\{b_{2}\left[\rho^{2} \Lambda_{o}+\left(\phi_{y}-\sigma \kappa_{y} \frac{\phi_{\pi}-1}{\sigma\left(1-\rho^{2}\right)+\phi_{y}}\right)\left(1-\rho^{2}\right)\right]+\phi_{y} \omega_{\pi}+\sigma \kappa_{y} \omega_{y}\right\}
$$

After some algebra, it can be expressed as:

$$
b_{o}+b_{2}=\frac{1}{\Lambda_{0}}\left\{\frac{b_{2} \phi_{y}}{\sigma\left(1-\rho^{2}\right)+\phi_{y}}\left[\Lambda_{2}+2\left(1-\beta \rho^{2}\right) \sigma(1-\rho)^{2}\right]+\phi_{y} \omega_{\pi}+\sigma \kappa_{y} \omega_{y}\right\}
$$

Replace the definition for $b_{2}$ :

$$
b_{o}+b_{2}=\frac{1}{\Lambda_{0}}\left\{\phi_{y}\left(\Omega_{\pi}+\Omega_{m c}+\Omega_{v}\right)(1+\Psi)+\phi_{y} \omega_{v}+\sigma \kappa_{y} \omega_{y}\right\}
$$

where $\Psi=2\left(1-\beta \rho^{2}\right) \sigma(1-\rho)^{2} / \Lambda_{2} . \Psi$ is positive and very small for $\rho$ close to 1 


\section{Appendix: Calculation of share and elasticity}

\section{C.1 Calculation of $\bar{\alpha}$}

From the steady state demand for oil we can obtain the following:

$$
\begin{aligned}
\overline{\bar{Y}} & =\alpha^{\psi}(\overline{Q / M C})^{-\psi} \\
& =\alpha^{\psi}(\overline{Q / M C})^{1-\psi} /(\overline{Q / M C}) \\
& =\bar{\alpha} /(\overline{Q / M C})
\end{aligned}
$$

Then, from this equation, $\bar{\alpha}$ is equivalent to:

$$
\bar{\alpha}=\mu \frac{\overline{Q M}}{\bar{Y}}
$$

We use data from IO tables the National Income Product accounts (www.bea.gov) for the U.S. to obtain an estimate of $\frac{\overline{Q M}}{\bar{Y}}$ as the ratio of Oil and other fuels used for production/ Value added. To compute this ratio we follow Blanchard and Galí (2008) methodology, considering the U.S. economy as having two sectors, an oil-producing sector and a non-oil producing sector. The oil producing sectors considers the sum of the "oil and gas extraction" sector (NAIC code 211 ) and "petroleum and coal" sector (NAIC code 324). The non-oil producing sector considers the rest of the economy. Because of availability, we use data for the following years: 1972, 1977, 1987, 1992 and 1997 to 2006. The average value of $\frac{\overline{Q M}}{\bar{Y}}$ from 1972 to 2006 is $2.5 \%$. Considering an average mark-up of $15 \%$ ( $\mu=1.15)$, the estimated value of $\bar{\alpha}$ is $2.875 \%$.

\section{C.2 Calculation of $\psi$}

The log-linearization of the demand for oil $\left(m_{t}\right)$ is the following:

$$
m_{t}=-\psi\left(q_{t}-m c_{t}\right)+y_{t}
$$

which after replacing the definition of marginal costs and the equilibrium real wages, it becomes:

$$
m_{t}=-\psi \chi q_{t}+(1+\psi \chi(\nu+\sigma)) y_{t} .
$$

We estimate equation (C.2) in differences, considering the following data $m_{t}: \log \mathrm{SA}$ quarterly petroleum consumption in the US in numbers of barrels per day - sum of all sectors (Energy Information Administration, July 2008 Monthly Energy Review). $q_{t}$ : log spot oil price 
West Texas Intermediate (PZTEXP) minus log SA non-farm business sector deflator (LXNFI). $y_{t}: \log$ SA non-farm business sector output (LXNFO) - log civilian non-institutional population aged above 16 (LNN). Our data is quaterly and corresponds to the period 1970.1-2005.4

The estimated equation is :

$$
\begin{array}{rlllll}
\Delta m_{t}= & -0.0027 & -0.0207 & \Delta q_{t} & +0.4999 & \Delta y_{t} \\
& (0.1610) & (0.0629) & & (0.007) &
\end{array}
$$

$p$-values in parenthesis. Because the value of $\chi$ is very close to 1 , the estimated value of the elasticity of substitution of oil is $\psi \approx 0.02$. To avoid well known bias associated to the endogeneity of output and oil demand, we estimate the previous regression using as instrumental variables lags of the changes of output. 